\title{
LOS PRIMEROS "YUGOS" VERACRUZANOS
}

Por John F. Scott

Universidad de Cornell

Durante los últimos quince años, nuevas exploraciones arqueológicas en el Estado de Veracruz han permitido conocer tres sitios en los cuales se hallaron cinco ejemplares de los llamados "yugos" votivos; éstos se encontraron in situ y no solamente como relleno sino como ofrendas en entierros. Los tres sitios son: El Carrizal, municipio de Emiliano Zapata, excavado por la arqueóloga Bertha Cuevas de Alvarez; Santa Luisa, municipio de Gutiérrez Zamora, excavado por el arqueólogo doctor Jeffrey Wilkerson; y El Zapotal, municipio de Ignacio de la Llave, excavado por el arqueólogo Manuel Torres Guzmán. ${ }^{1}$ Estos descubrimientos, aunados a los yugos asociados a entierros en los sitios de Cerro de las Mesas y El Viejón, de los cuales se tenía noticia desde hace tiempo, nos presentan con una serie de ejemplos, más o menos continua en el tiempo, que muestra el uso funerario al cual se adaptaron los yugos; no creo, sin embargo, que éste fuera el uso principal al cual se les tenía destinado durante la vida de los señores a quienes más tarde acompañaron al sepulcro.

Los yugos de El Carrizal, excavados en 1961 (García Payón, 1971: 524), son probablemente los más tempranos, ya que provienen de un sitio que, según la arqueóloga Cuevas, pertenece casi en su totalidad al Preclásico Superior (Cuevas, 1970, ms.: 81). Posteriormente me referiré de nuevo a su fechamiento, por ahora es suficiente tener en cuenta que el entierro de El Carrizal precede cronológicamente a los otros cuatro ya mencionados. Dos yugos labrados en forma de sapo acompañaban al entierro secundario número 2 del montículo 38 de El Carrizal (figuras

1 Quisiera dar las gracias a los investigadores del Instituto de Antropología de la Universidad Veracruzana de Jalapa por haberme proporcionado informes y permitido el acceso a las colecciones del Museo, así como el poder usar la Biblioteca para realizar mi trabajo, sobre todo al Archivo Técnico. El director del Instituto, el arqueólogo Alfonso Medellin Zenil, y la encargada de las colecciones, la arqueóloga Bertha Cuevas de Alvarez merecen especialmente mi agradecimiento. Gracias a la donación del National Endowment for the Humanities bajo un Younger Humanist Fellow-ship, me fue posible vivir en Jalapa y realizar la investigación sobre el estilo posolmeca en Veracruz. Para poder dedicarme a escribir las conclusiones recibí la ayuda de Faculty Research Grant del College of Arts and Sciences of Cornell University. 
8 y 9). Los grandes huesos del difunto fueron dispuestos dentro de una gran olla globular a la cual se cubrió con un apaxtle de otro tipo de barro (figura 1). Cada yugo fue roto en dos partes -probablemente indicando que se les "mató" ceremonialmente- y los cuatro pedazos se colocaron entre las ofrendas de cerámica, en ángulos inclinados que no parecen indicar ningún uso en particular (Cuevas, 1970, ms.: 78). A un lado, y en el mismo nivel, apareció otro entierro secundario, el número 1 , el cual no tiene ofrendas y posiblemente acompañaba al anterior.

En el año de 1941, en Cerro de las Mesas, se descubrió, por vez primera en una excavación controlada (en este caso por Stirling y Drucker), un yugo asociado a un entierro. En el montículo principal explorado por medio de la trinchera 30 , encontraron un entierro, el in-18, que contenía un cadáver, cuya calavera y mandibula estaban separadas del cuerpo. Drucker (1943:9, cuadro 2) pensó que se trataba de un decapitado o de un entierro secundario. Por su parte, Stirling afirmó que se trataba de una decapitación (1941:23), pero Krutt, basándose en el hecho de que la mandibula se encontró aparte, fue de la opinión que podia considerarse como entierro secundario. Dentro de la misma plataforma había otros dos entierros que evidentemente sirvieron de acompañantes al II-18, ya que sus ofrendas eran pobres en contraste con el mismo; en uno de ellos, el 11-20, el cuerpo, extendido parcialmente, estaba decapitado. El entierro II-18 contaba con una rica ofrenda consistente en un conjunto de vasijas cuyas formas, esbeltas y elegantes, permitían fecharlas en el Protoclásico (Coe, 1965; 697-698). Drucker, sin embargo, las situó en la fase inferior il y, por lo tanto, resultarian contemporáneas a las ofrendas localizadas en la parte superior del montículo secundario (1943: 79-81), a pesar de que dicho montículo mostraba gran número de rasgos teotihuacanos. Insisto en el fechamiento de las ofrendas del montículo principal en el Protoclásico, puesto que son típicas de dicho periodo; tenemos, por ejemplo, un soporte de vasija de forma cilíndrica que corresponde, tanto por su forma (que asemeja una orejera) como por su decoración pintada sobre estuco, a un tipo de soporte semejante, común en Monte Albán II (Caso, Bernal y Acosta, 1967: 250); y un carapacho de tortuga, cuyos diseños incisos pertenecen al estilo izapeño (Coe, 1965: 697). Un yugo liso, que no fus fragmentado, estaba colocado a un lado y a $30 \mathrm{~cm}$ de la ofrenda de cerámica (Drucker, 1943, lámina 6); lo acompañaban dos figurillas de barro, la de mayores dimen- 
siones puede compararse, por sus rasgos naturalistas y elegantes, a las figuras-efigies de Monte Albán II.

En la trinchera 3 del Viejón, municipio de Actopan, se descubrió un yugo liso, fragmentado; la cerámica hallada a su derredor correspondía al estilo Remojadas Superior (Medellín, 1951, ms.: 67A); entre esta cerámica, en el entierro 5 , se encontró una vasija trípode, cilíndrica, con grabados felinos que está relacionada intimamente a formas teotihuacanas de la fase in, o sea Xolalpan Temprano (450-550 d. C). El entierro número 12, asociado a un yugo y una hacha (esta última representando la cabeza de un anciano), no tenía cerámica a excepción de un apaxtle que contenía los huesos, que según Medellín, estaban "casi pulverizados y protegidos por el arco del fragmento mayor del yugo, revueltos con pequeños fragmentos de cinabrio" (Medellín, 1960: 187).

Dos yugos fueron descubiertos en El Zapotal durante la cuarta temporada de excavaciones dirigida por Torres Guzmán (1974, ms). De los tres niveles de entierros encontrados en la trinchera $\mathbf{I X}$, fue en el intermedio donde apareció un yugo acompañando un entierro primario (el número 15). En el nivel más profundo, en otro entierro primario, el número 20, se sacó a luz otro yugo (Jaime Ortega, informe personal). En ambos entierros el cadáver parece haber sido colocado en posición sedente, a un lado del yugo correspondiente, y cada uno estaba asociado a una cabeza-hacha, cuya muesca, proyectada hacia atrás, podría haber vacido originalmente sobre uno de los lados del yugo. Esta posición corresponde a la que propone Ekholm en relación al uso original de las hachas (Ekholm, 1973: 48).

El yugo más tardío de los cinco sitios es el encontrado en el entierro primario número 15 de Santa Luisa; este sitio es, entre todos, el que se localiza más al norte. Dicho entierro muestra la asociación más directa entre el señor enterrado, en este caso un joven, y el yugo. El cadáver se colocó sentado encima del yugo y con las piernas extendidas sobre el lado recto del mismo (Wilkerson, 1970: 42). La única pieza de cerámica hallada fue un gran apaxtle que cubría todo el entierro. La ofrenda contenía dos pedazos de metates, un tipo de objeto nunca antes asociado a un yugo. A medio metro de este entierro se excavó otro, de un hombre un poco más viejo, al cual se le enterró sin mayor cuidado en un pozo; su ofrenda, de menor riqueza, incluía un tubo de cobre. Basándose en estos datos, Wilkerson (1970: 44) dedujo que se trataba de un acompañante del joven señor, que fue sepultado en el Postclásico 
Temprano, periodo en el cual se empezaron a emplear los metales. Los dos entierros fueron colocados en pozos que pueden calificarse como intrusos dentro de una plataforma construida a fines del Clásico. Un fragmento de yugo tallado en serpentina verde y que proviene de la trinchera 2 de Santa Luisa (Wilkerson, 1972, ms.: 727) puede fecharse en la misma época (c. 900 d. C).

De estos datos se infiere que durante la época temprana los yugos eran, al igual que la cerámica o cualquier otra posesión del difunto, simples ofrendas; estos yugos se colocaban rotos $y$, en muchos casos, sin relación al cadáver, el cual ya se encontraba descarnado. Más tarde, en el Clásico Tardio y principios del Postclásico, los cadáveres todavía completos fueron colocados en posición sedente, en intima asociación con los yugos, los cuales, además, no se fragmentaban. En el Clásico Medio (verbigracia: El Viejón y El Zapotal), los yugos tenían dispuestos a sus lados cabezas-hachas, del tipo grueso. Los tres sitios que pertenecen al Clásico (considerando al ejemplo de Santa Luisa como una extensión de dicho periodo) sugieren el uso propuesto por Lothrop (1923) y por Ekholm (1946), en el sentido de que los yugos servian como cinturones en el juego de pelota. Aunque ninguno de los difuntos llevaba el yugo puesto, puede observarse que al paso de los siglos, estos objetos se disponían cada vez más cerca de los cadáveres, hasta llegar al caso de Santa Luisa, en que el señor estaba sentado sobre un yugo.

Algunos hallazgos de yugos en contextos evidentemente funerarios fueron dados a conocer, en 1926, por el investigador aficionado de nacionalidad francesa, Auguste Génin, pero bajo condiciones que actualmente considerariamos como de saqueo. En Paraíso Novillero, municipio de Cosamaloapan Veracruz le tocó a un colega de Génin obsevar un pozo hecho por peones, del cual se había obtenido un yugo entero en forma de sapo-monstruo (Génin, 1928:524, figura 1); este yugo se encontró sobre el lugar de donde se sacaron los huesos de muerto. No es posible determinar la fecha de este hallazgo por la razón de que no se ha podido localizar el vaso de barro rojo sacado del mismo pozo, el cual fue calificado por Génin como "de una pureza admirable en su forma" (1928: 524). El segundo descubrimiento tampoco fue visto por Génin, sino por unos indios que saqueaban un montículo a un lado del pueblo de Omealca, Veracruz (1928:525).

El entierro encontrado por Génin y su anfitrión Peñafiel, cuya foto 
fue reproducida de nuevo por Krutt (1969:17), no corresponde en sus características a ninguno de los hallazgos que acabamos de describir. El yugo liso, invertido, rodeaba la calavera como si fuera una corona; sus extremidades abiertas estaban hacia abajo y la apertura se rellenó de un rollo hecho de madera de cedro. Creo yo que es muy dudoso que Ia madera resistiera, sólo deshaciéndose un poco, el transcurso de un milenio o más en la tierra mojada de la sierra de Zongolica. También resultá dudoso el arreglo de los huesos observable en la foto, ya que da la impresión de que los indios reconstruyeron la forma de un entierro primario, después de que ellos perturbaron la colocación original. Sospecho que los peones alquilados por Peñafiel querían agradarlo, mostrándole un hallazgo de especial interés. Aunque el entierro estaba acompañado de cuentas, puntas de flecha de obsidiana y un pedernal, carecía de cerámica que permitiera fecharlo.

En otros casos que han aparecido yugos: en Tres Zapotes (Weiant, 1943:118), Las Higueras (Avellanos Melgarejo, informe personal) y Palenque (Ruz, 1952:58; y 1958:140), se trata solamente de pedacitos de estos objetos usados como relleno de construcciones posteriores 0 , quizá, como ofrendas. Los dos yugos lisos y la cabeza-hacha de Xochicalco seguramente formaban parte de una ofrenda de la Cámara de las Ofrendas del Edificio A (Sáenz, 1962:21), erigido sobre un entierro primario, flexionado. Según la lápida calendárica que los acompañaba, su fecha correspondería a finales del Clásico (Sáenz, 1974:181).

La antigüedad de los yugos no ha sido fijada con precisión a pesar de los hallazgos de los cinco sitios ya anotados. En una síntesis, del arte clásico del centro de Veracruz, Proskouriakoff escribió (1971:559).

Yokes and hachas may originate at about the same time, though we do not have a firm association of either of these forms with Preclassic or Protoclassic ceramics. García Payón (1947:327) reports a plain yoke that apparently came from a late Preclassic deposit at E1 Trapiche, Veracruz, but he expresses doubt of the validity of this association.

Las dudas de García Payón sobre la asociación del yugo liso recuperado durante la excavación de rescate en El Trapiche (1942) están bien fundamentadas. Dos trabajadores rescataron al yugo por medio de ganchos antes de que se desprendiera del borde de un montículo. Aunque no fue posible confirmarlo por la estratigrafia, García Payón consideró que procedía de los niveles intermedios del montículo (1966: 
180). Puesto que el sitio de El Trapiche, municipio de Úrsulo Galván; contenía cerámica que abarcaba desde el Preclásico Temprano hasta el Tärdio, García Payón consideró que el yugo pertenecía al Preclásico Medio (1971:525).

Tampoco ha sido posible encontrar antecedentes bien definidos de los yugos en la pequeña escultura en piedra. Los llamados "yuguitos" que provienen del área de Tlatilco y de Guerrero no parecen encontrarse en el Estado de Veracruz (Coe, 1965 a:21). No hay duda del origen olmeca del ejemplo ilustrado por Peterson y Horcasitas (1957:1ámina II) que actualmente se encuentra en el Museo de Arte Primitivo de Nueva York. Los yuguitos, al igual que los verdaderos yugos, muestran un excelente pulido, además de tener talladas, en su superficie exterior, volutas y formas humanas retorcidas; pero su tamaño tan reducido excluye la posibilidad de que se usaran como cinturones; además, la disposición de los grabados sugiere una posición vertical, y no horizontal, como la de los yugos. Otro rasgo que los diferencia de los yugos es su forma interna cóncava, delgada, y no convexa y redonda como en el caso de los primeros. Seguramente tenían otra función, ya sea como protectores de manos, como sugirió Julie Jones (Coe, 1965a:21) o de las rodillas o codos (Peterson y Horcasitas, 1957:365).

Verdaderos yugos miniaturas aparecieron en el relleno del sitio de Las Higueras, municipio de Vega de Alatorre (figura 3). Su posición estratigráfica permitió al arqueólogo, Ramón Arellanos Melgarejo, asignarlos al Protoclásico (informe personal). Pero, como veremos, los primeros yugos fechados con seguridad pertenecen también al Protoclásico, por lo tanto, los pequeños yugos de Las Higueras, que miden entre $9.5 \mathrm{~cm}$ hasta $16.5 \mathrm{~cm}$ de largo, no pueden considerarse como antecedentes de los grandes (que miden más de $40 \mathrm{~cm}$ de largo), sino como copias en miniatura. En el sitio de El Carrizal también se halló un ejemplo de yugo miniatura (Guevas, 1970:71; foto 52). Cualquiera que fuese su función, votiva o de juguete con fines didácticos, estos objetos sí merecen el apelativo de "yuguitos".

¿Qué tan temprano son entonces, los dos yugos en forma de sapo-monstruo que vienen del Carrizal? Ya sabemos que la arqueóloga considera que todo el sitio pertenece a una sola época, la de Remojadas Inferior. La cerámica durante esta época, concentrada en la zona semiárida del centro de Veracruz (Medellín, 1960:9), tiene la apariencia general de la cerámica del Preclásico Tardio en la región sureña de Mesoamérica. 
DOI: http://dx.doi.org/10.22201/iie.18703062e.1976.46.1052
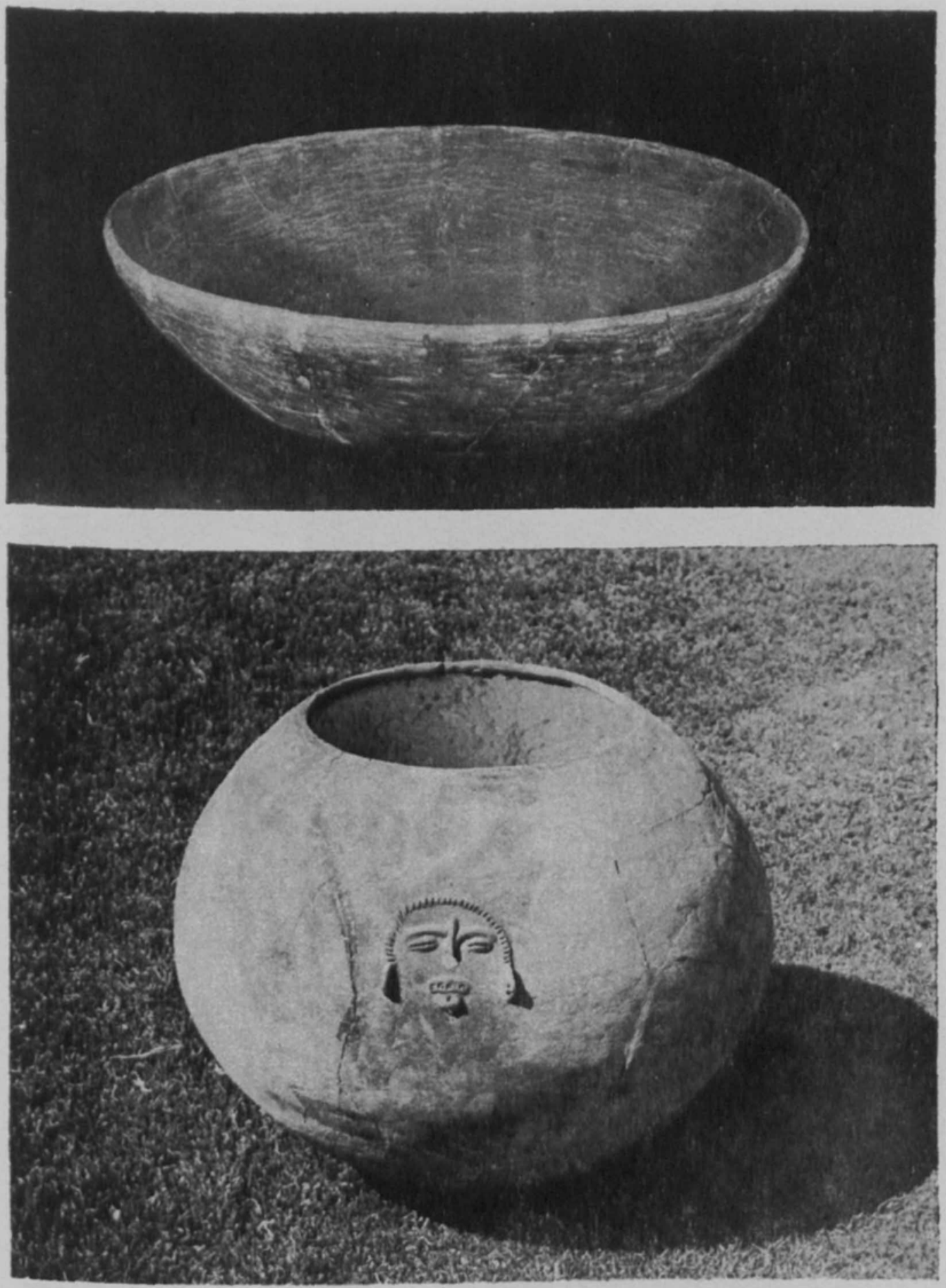

Figura 1. Olla globular de barro café, con cubierta. Carrizal, Veracruz. 
DOI: http://dx.doi.org/10.22201/iie.18703062e.1976.46.1052

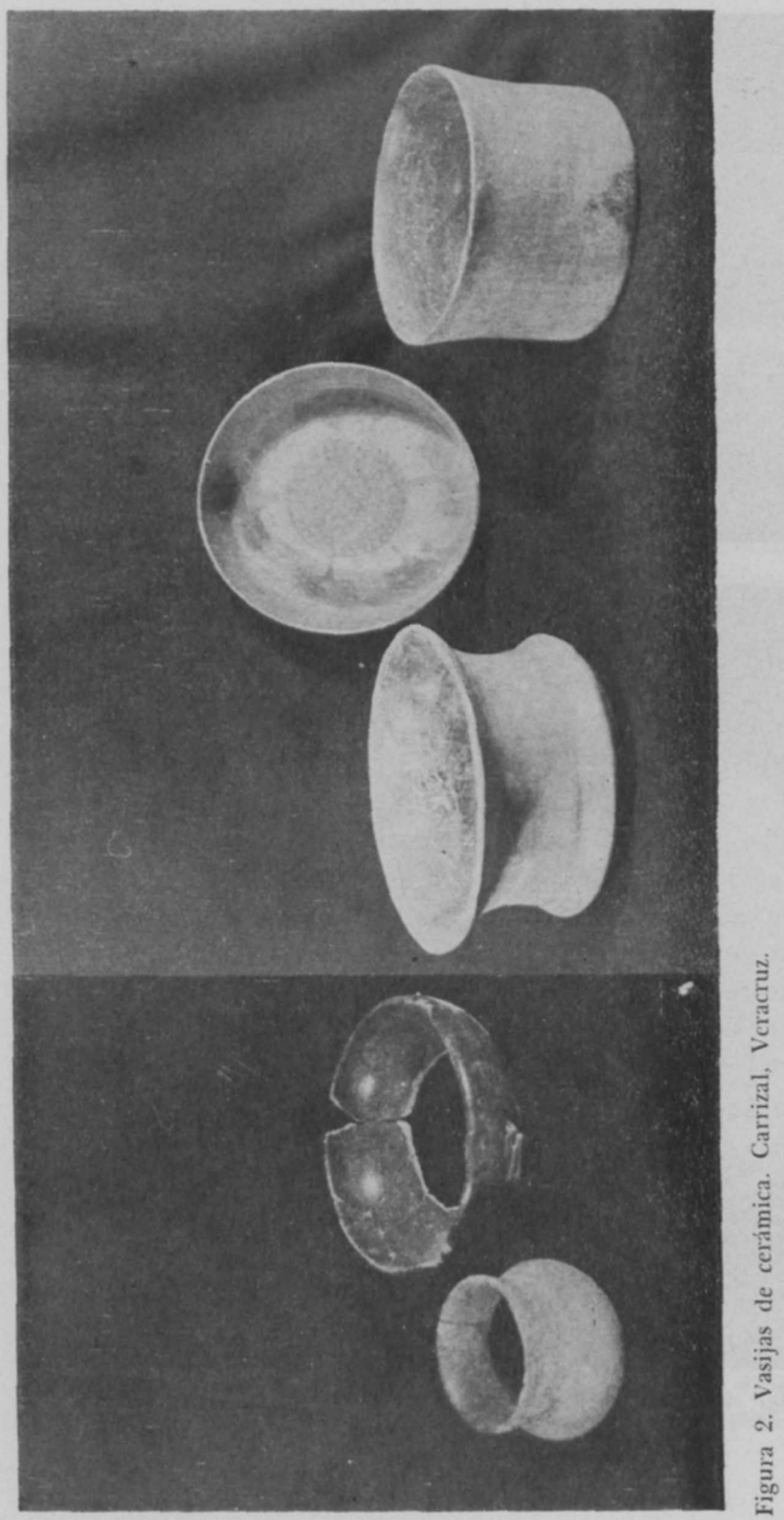


DOI: http://dx.doi.org/10.22201/iie.18703062e.1976.46.1052

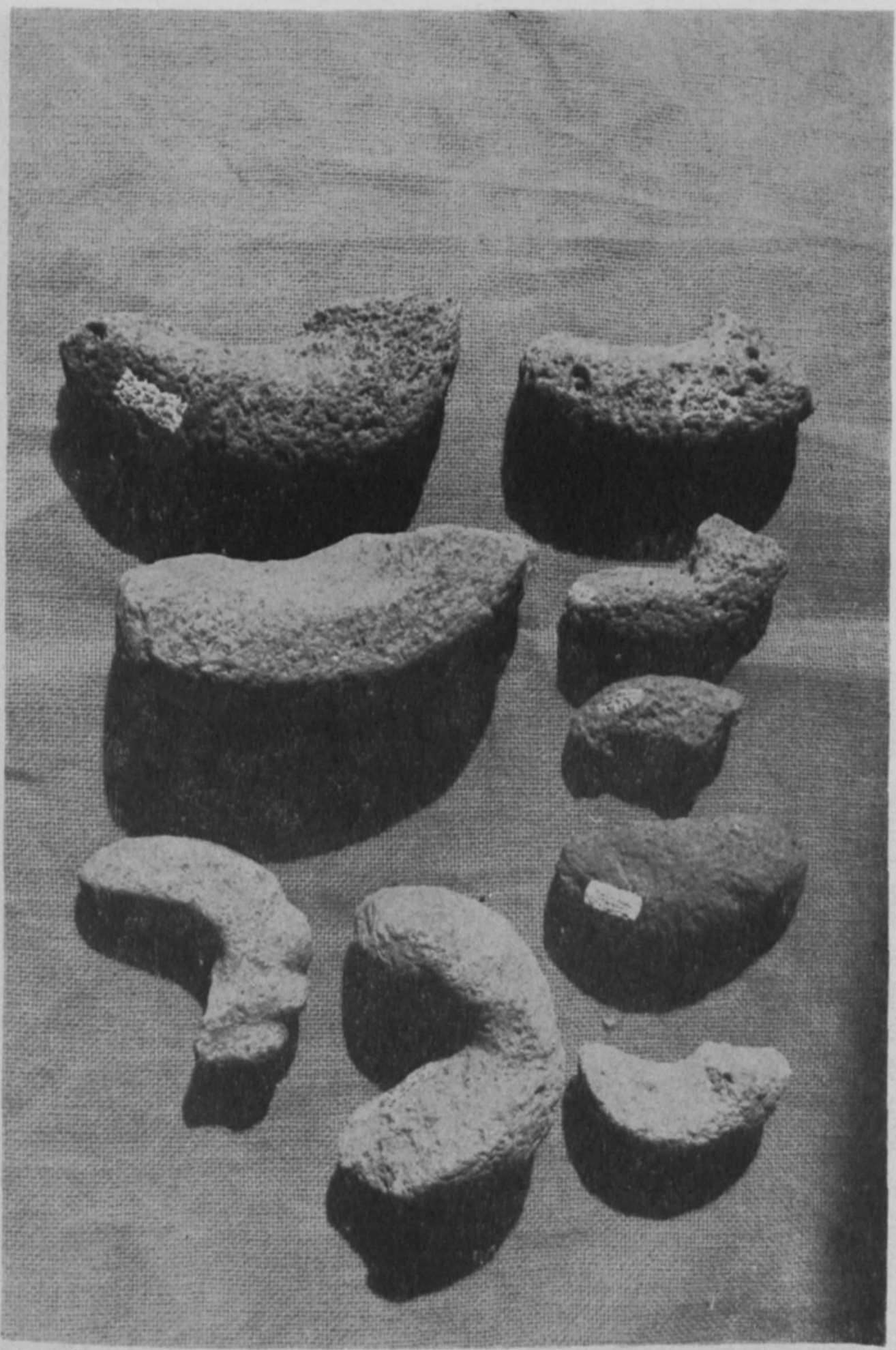

Figura 3. Fragmentos de yuguitos de piedra. Las Higueras, Veracruz. 
DOI: http://dx.doi.org/10.22201/iie.18703062e.1976.46.1052

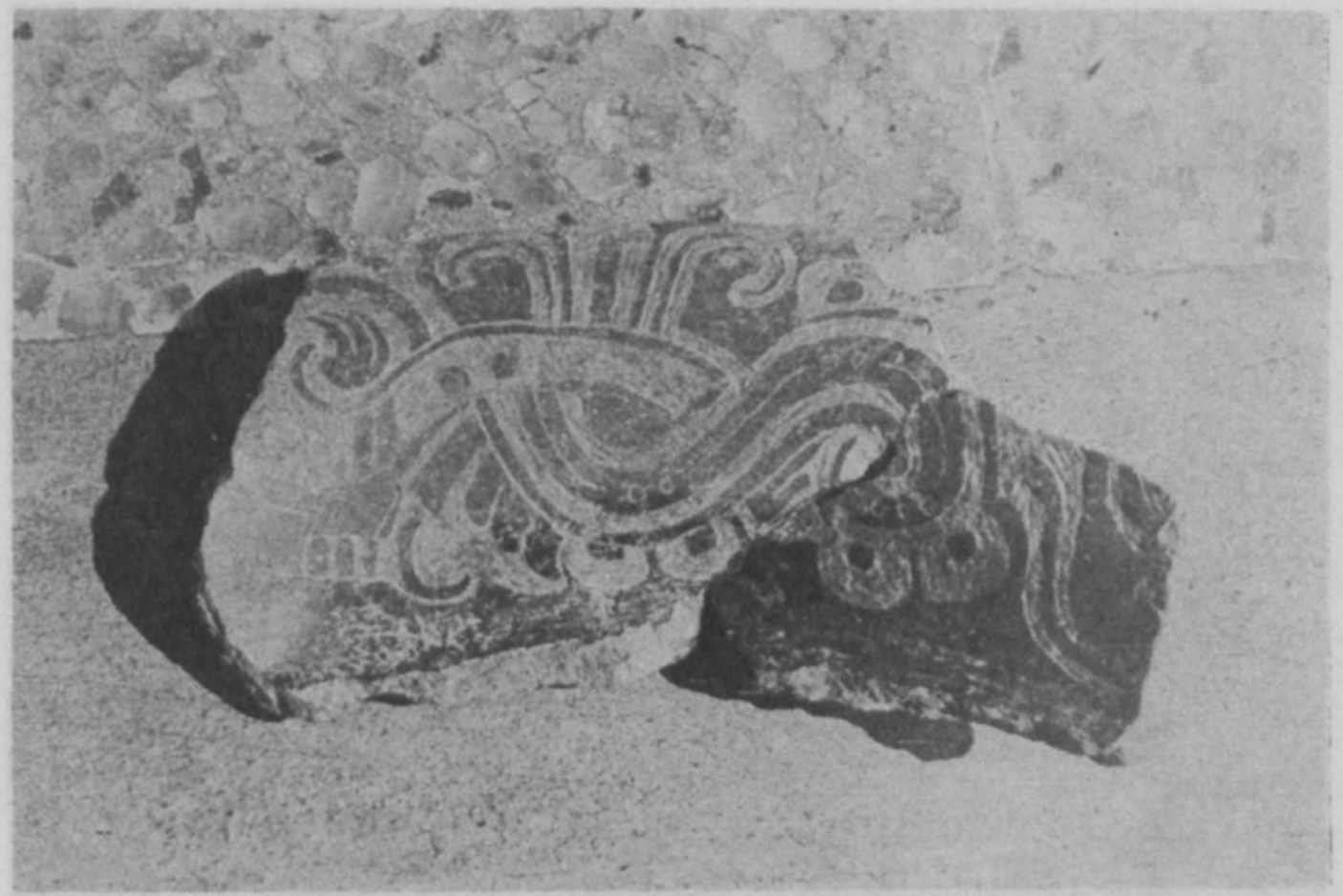

Figura 4. Fragmento de cajete de barro. Carrizal, Veracruz.

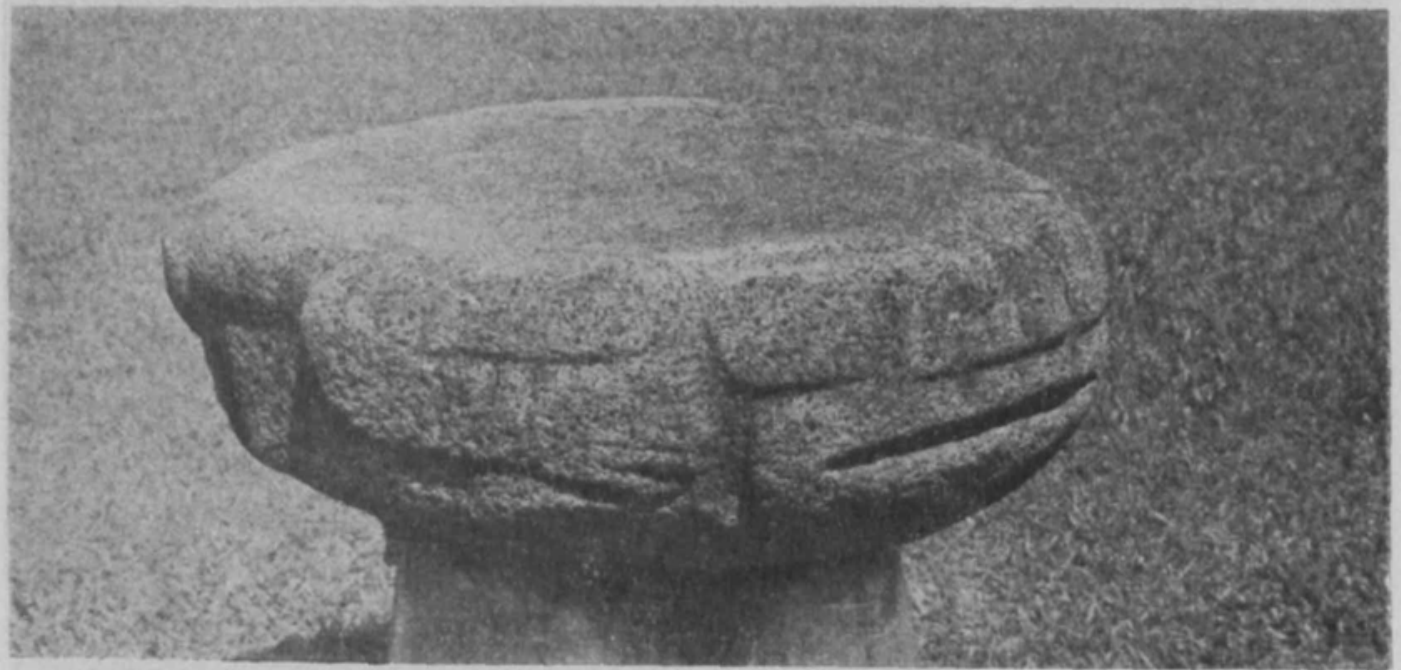

Figura 5. "Metate" de piedra en forma de sapo. Piedra Labrada, Veracruz. 
DOI: http://dx.doi.org/10.22201/iie.18703062e.1976.46.1052

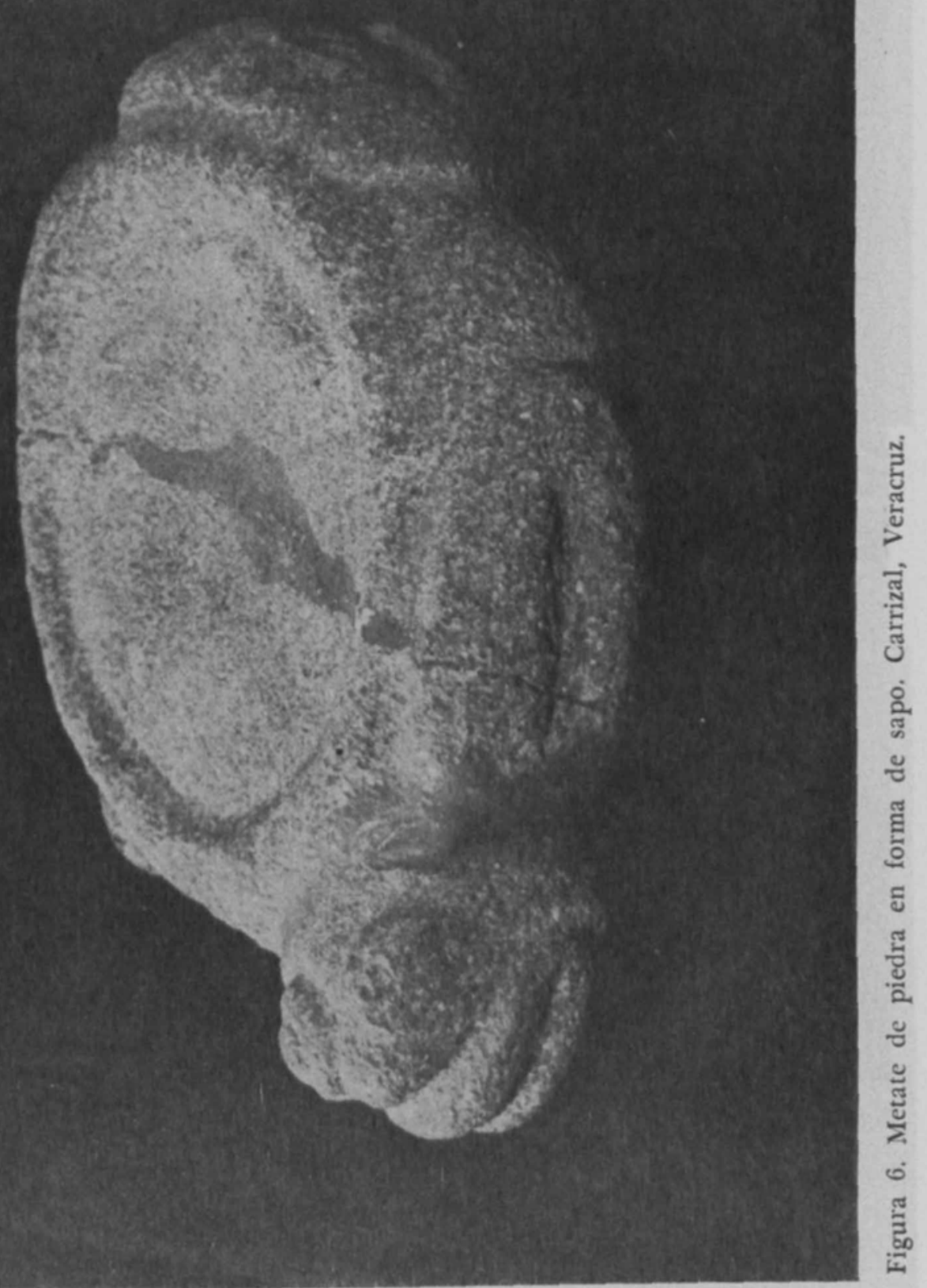


DOI: http://dx.doi.org/10.22201/iie.18703062e.1976.46.1052

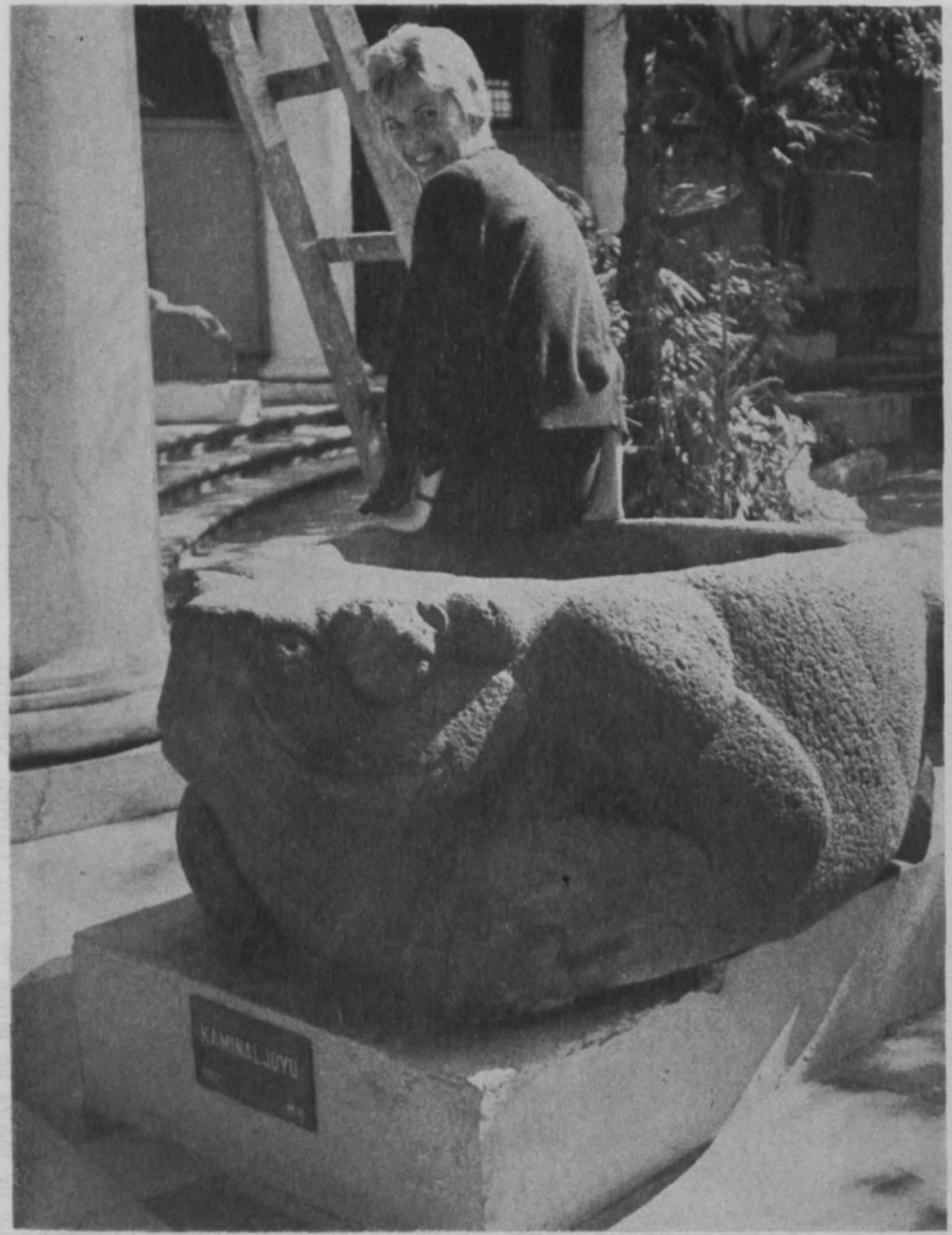

Figura 7. Altar 3, de piedra, en forma de sapo. Kaminaljuyú, Guatemala. 
DOI: http://dx.doi.org/10.22201/iie.18703062e.1976.46.1052

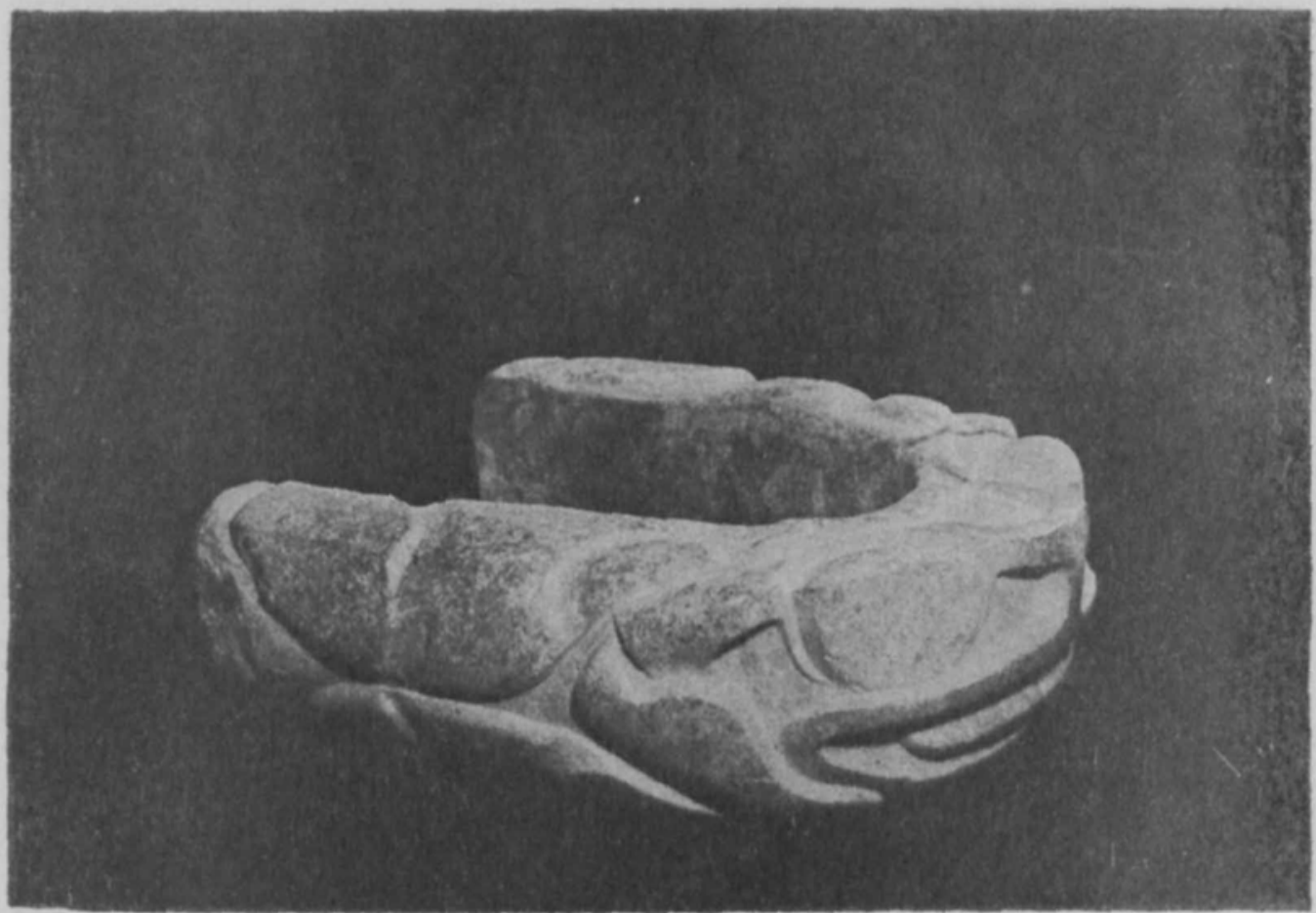

Figura 8. Yugo-sapo de piedra verde, Carrizal, Veracruz.

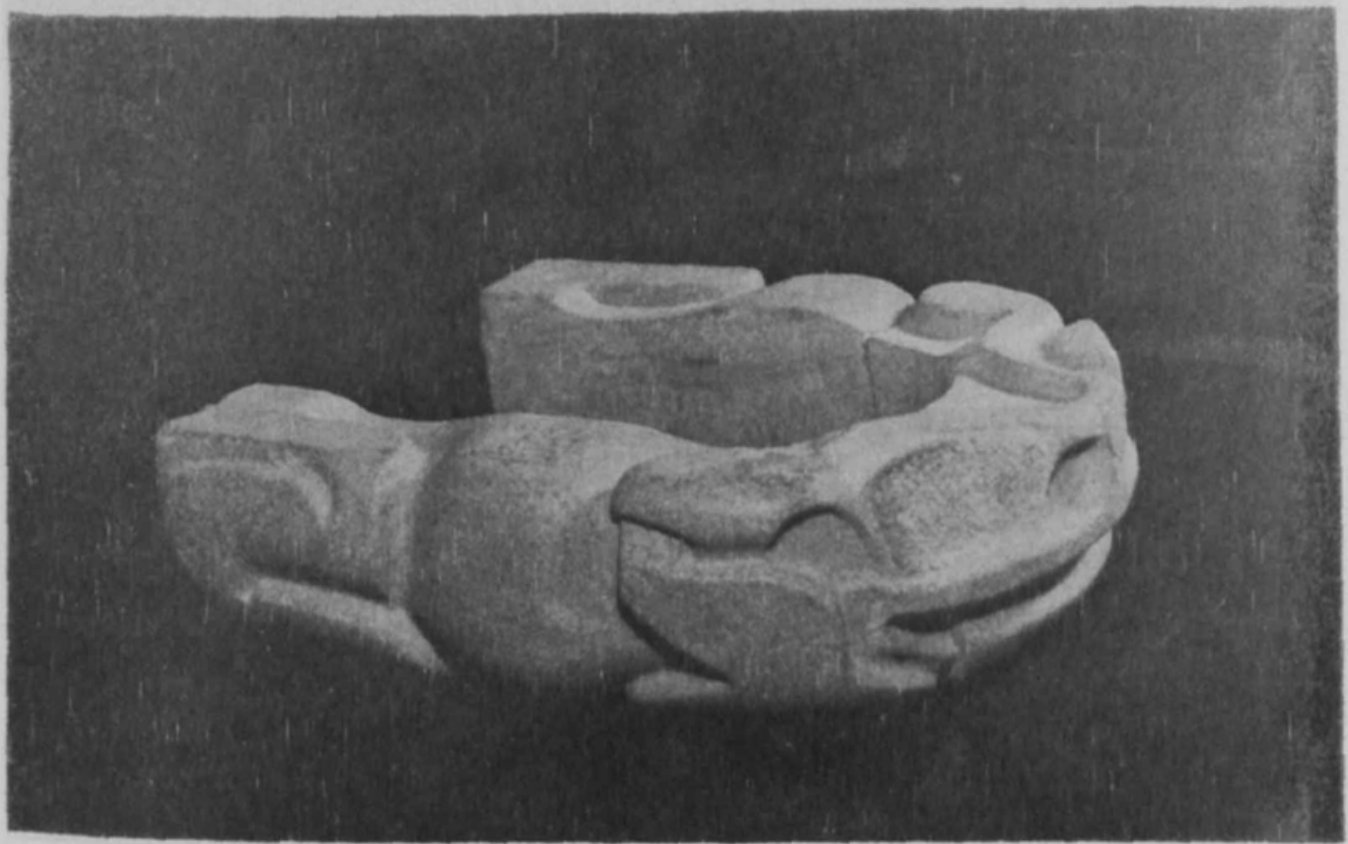

Figura 9. Yugo-sapo de piedra gris. Carrizal, Veracruz. 
DOI: http://dx.doi.org/10.22201/iie.18703062e.1976.46.1052

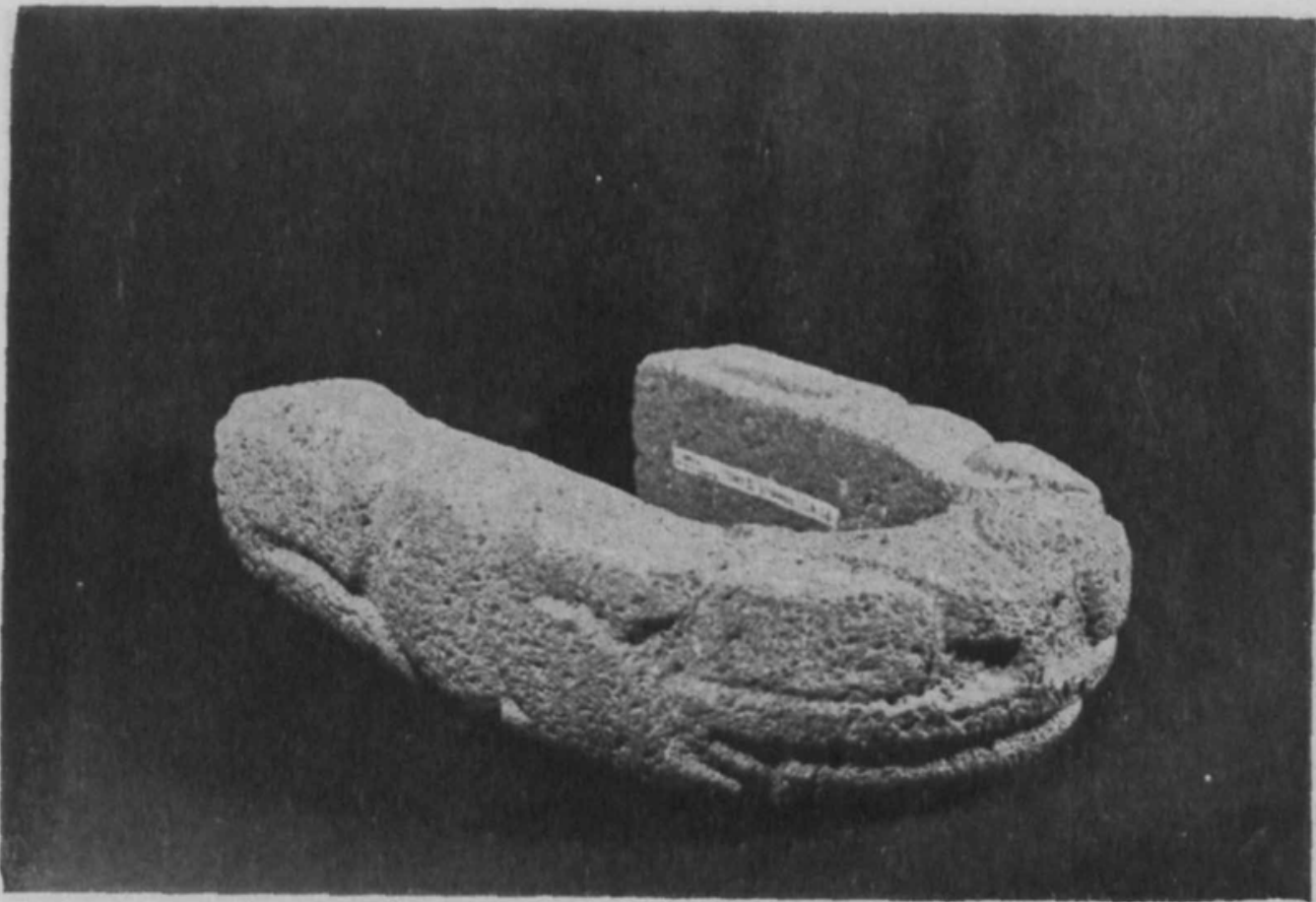

Figura 10. Yugo-sapo de piedra gris. Carrizal, Veracruz.

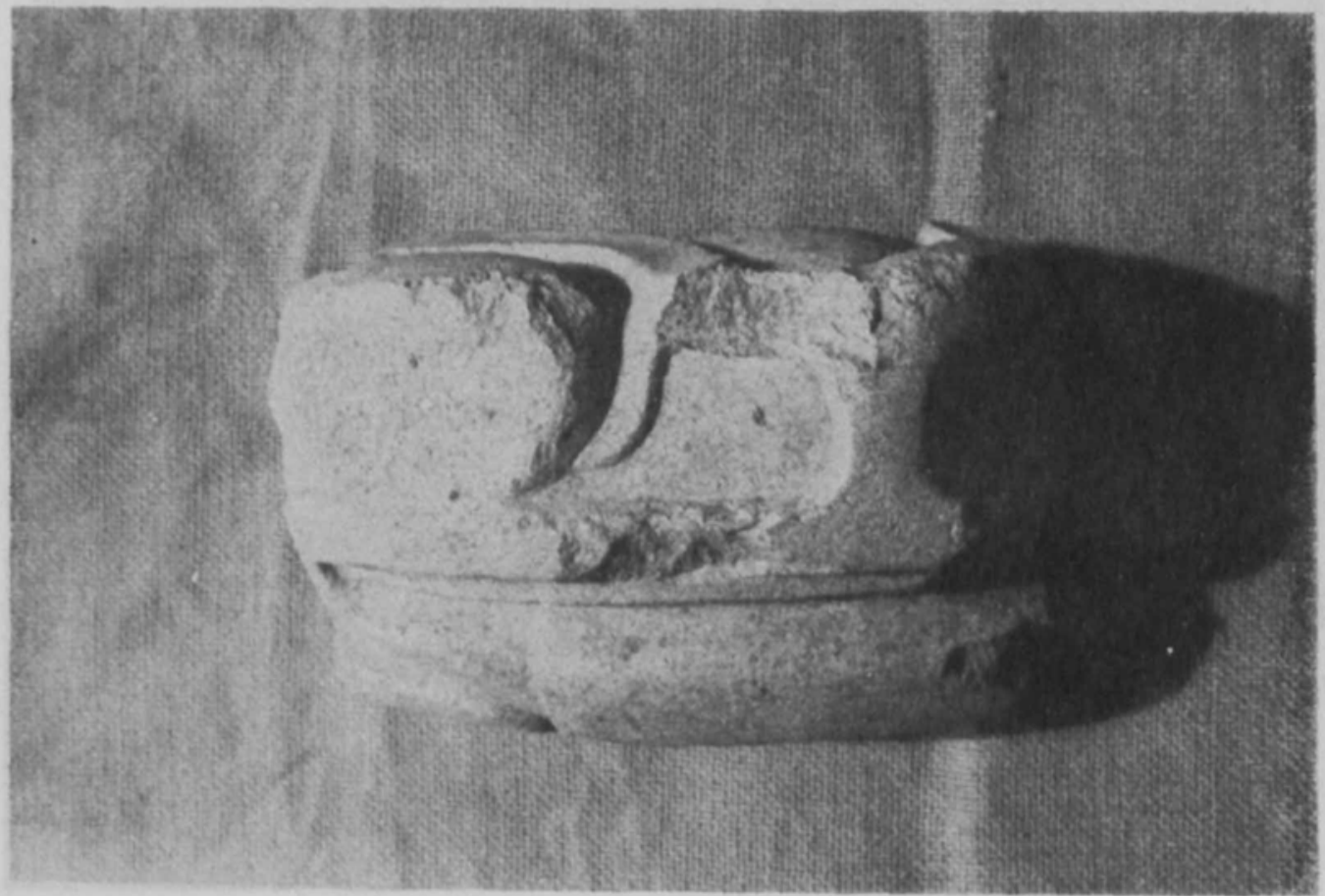

Figura 11. Fragmento de yugo-sapo de piedra. Las Higueras, Veracruz. 
DOI: http://dx.doi.org/10.22201/iie.18703062e.1976.46.1052

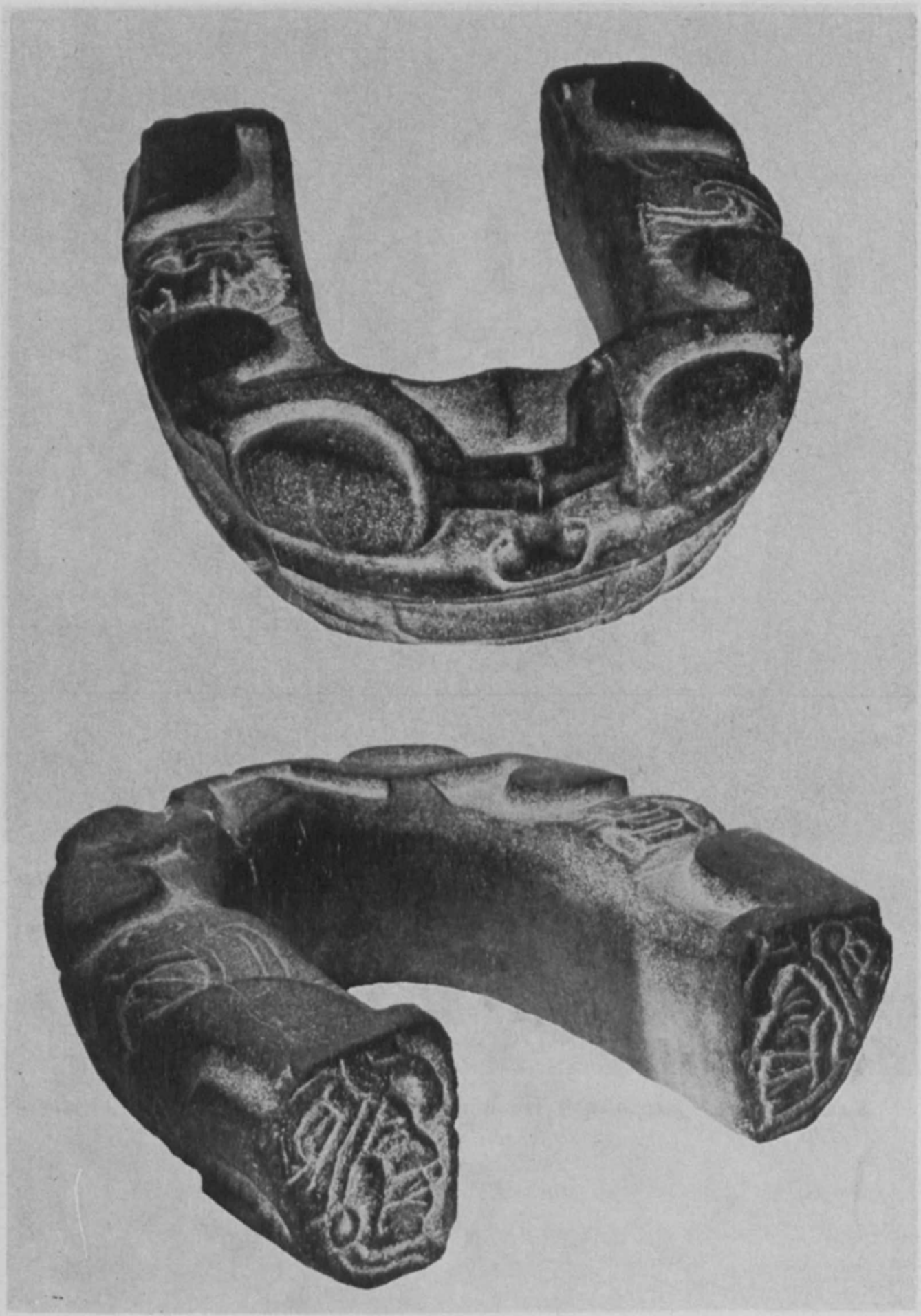

Figura 12. Yugo-sapo de diorita. Carrizal, Veracruz. 
DOI: http://dx.doi.org/10.22201/iie.18703062e.1976.46.1052

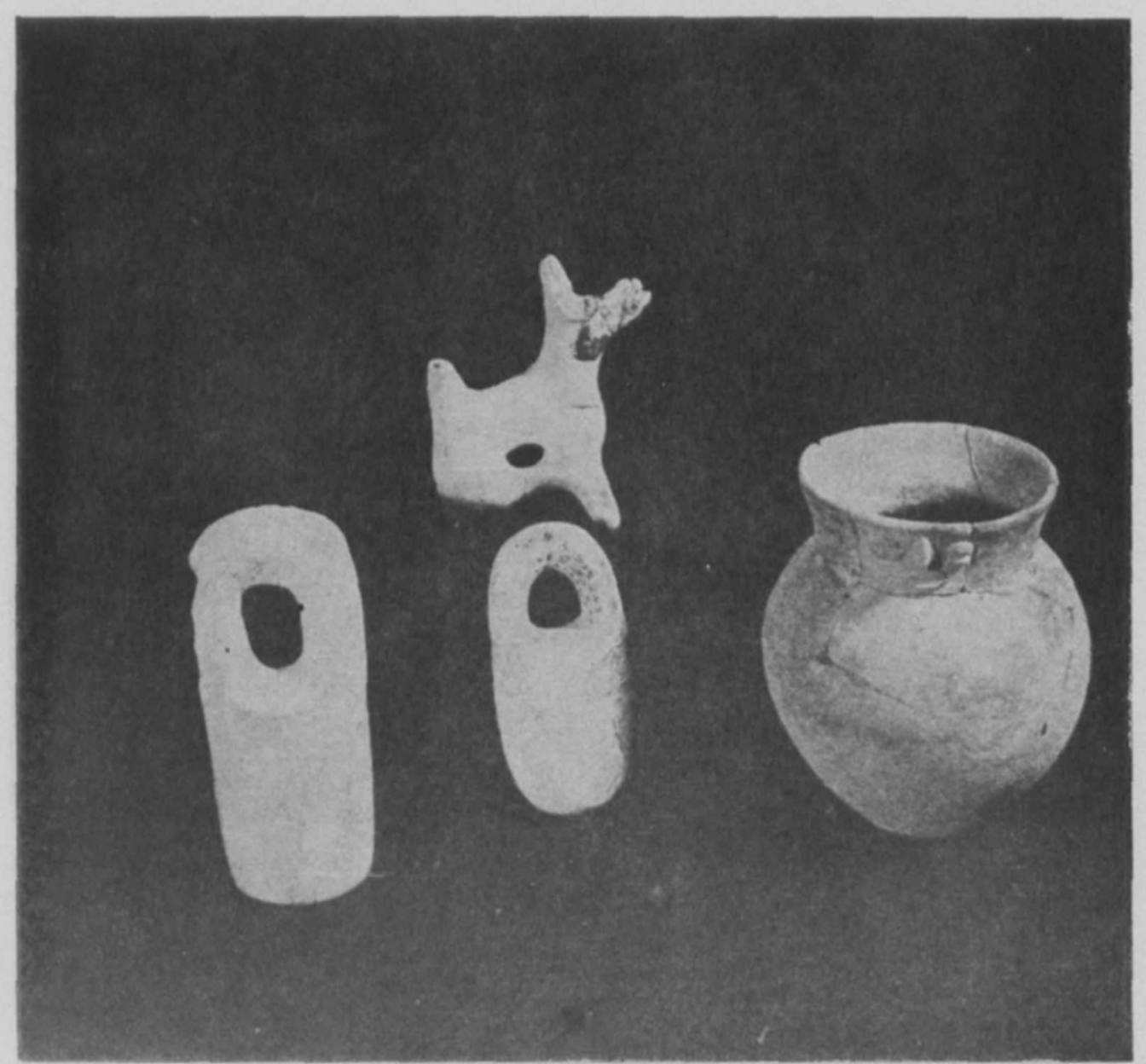

Figura 13. Macanas de piedra. Pito canino de barro. Olla efigie de barro. Carrizal, Veracruz. 
DOI: http://dx.doi.org/10.22201/iie.18703062e.1976.46.1052

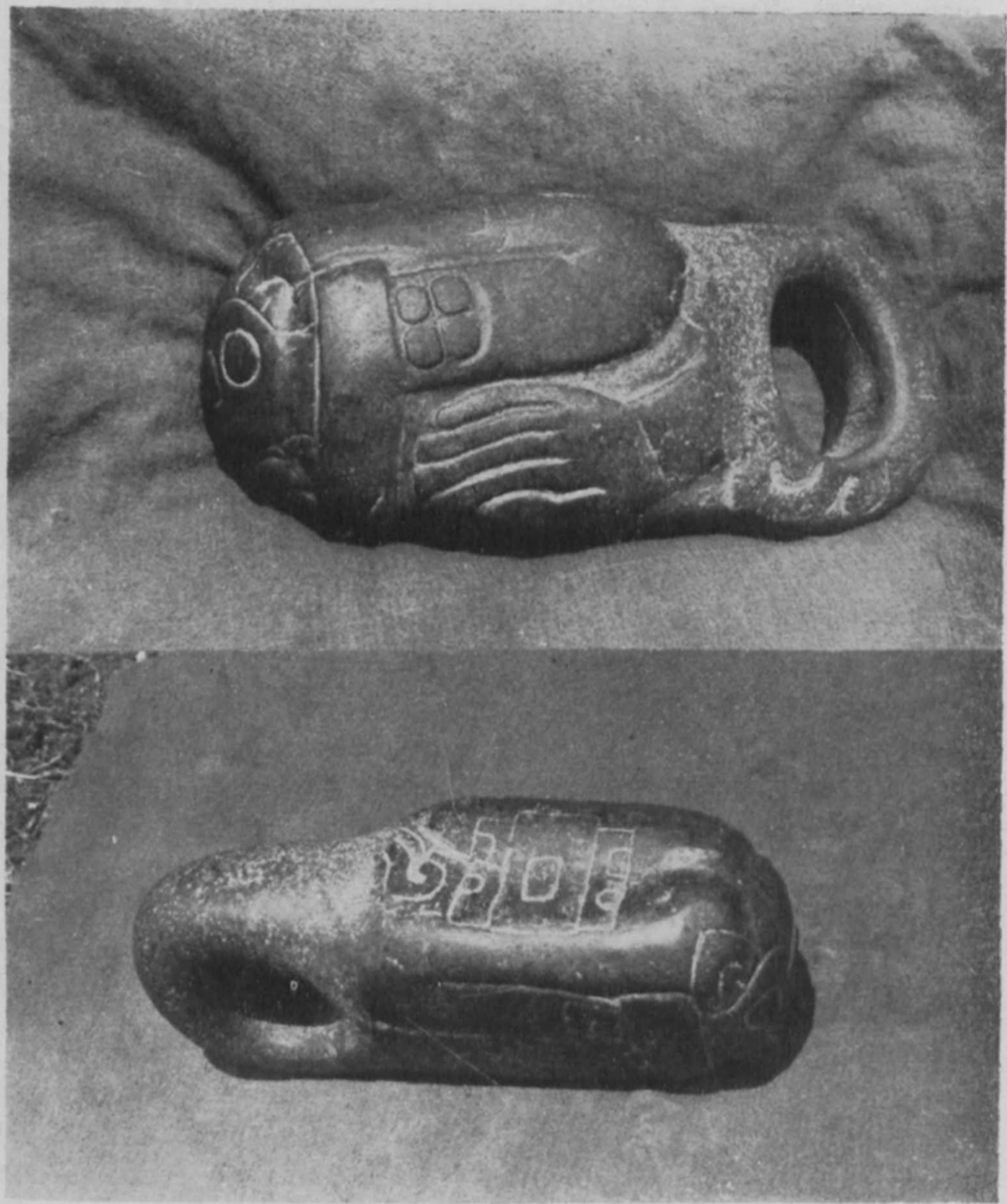

Figura 14. Macana de piedra verde. Cuenca del Papaloapan, Veracruz-Oaxaca. 
DOI: http://dx.doi.org/10.22201/iie.18703062e.1976.46.1052 
y aun así le faltan ciertos rasgos característicos de aquella época, como son: los bordes salientes o volados y con incisiones; los bordes-efigies; y los soportes mamiformes. A pesar de la ausencia de estos rasgos, que probablemente se pueda atribuir al fuerte regionalismo de Veracruz durante el Preclásico Tardío y el Clásico en su totalidad, las formas pulidas e incisas pueden continuar hasta el Protoclásico, como señaló Matheny $(1970: 51,118)$ en su comparación del Pimental Compositeblack campechano del Protoclásico (fase Tarpón, 50-300 d. C.) con el Baño Negro Pulido de Remojadas.

El estilo de Remojadas Inferior también incluye algunos rasgos que son comunes en el Protoclásico. Muchas veces las vasijas tienen fondos acanalados, como se encuentra en el Protoclásico Temprano en Chiapas (por ejemplo, el entierro con urna número l de Izapa; véase a Lowe, 1962, ms). También llaman la atención las partes inferiores de las vasijas, con un borde en la base, una silueta muy abultada hacia el fondo y un soporte en forma de rosca cilíndrica, como tienen los esbeltos vasos del entierro II-18 de Cerro de las Mesas (Drucker, 1943, lámina 20a, b) y los vasos de la fase Tecolutla $(100-300 \mathrm{~d}$. C), de Santa Luisa (Wilkerson, 1972 ms.: 305). Las ollas con asa vertedera, que son comunes en Remojadas Inferior, son igualmente populares en Monte Albán I y II, pero la segunda fase muestra las acanaladuras y el asa más vertical y recta, como en Remojadas.

Además de estas formas, muy generalizadas, hay otras provenientes de El Carrizal que sirven como rasgos distintivos ("marcadores") del Horizonte Protoclásico.

1. Tenemos, primero, la pintura negativa, hallada en Remojadas (Medellín, 1960, lámina 14) y El Carrizal, precisamente en el entierro que contenia los yugos (figura 2). Aunque ya no se considera que forma pirte exclusiva del Complejo $Q$ de Vaillant, sin embargo, es mucho más común durante el Protoclásico que durante cualquiera otra fase; se le encuentra en "Tres Zapotes Middle A" (Weiant, 1943: 124 y lámina 15k), así como en muchos sitios mayas, durante la fase Chicanel en el Petén, y las fases Guanacaste y Horcones (v-vi) en Chiapas (Peterson, 1963, figuras 17k, 57). Pero en el centro de México, esta técnica aparece más temprano, ocasionalmente en la fase Ticomán (Vaillant, 1931: 290, 387), y recientemente ha sido identificada en Tlapacoya durante el Preclásico Medio (Easby y Scott, 1970: 65). Sigue siendo muy popular durante el Protoclásico Temprano, que corresponde 
a Teotihuacan $1 ; 34 \%$ de los tiestos del interior de la Pirámide del Sol presentan decoración negativa (Schlenther, 1962: 84). En El Trapiche y Chalahuite, García Payón encontró "decoración negativa" en niveles que corresponden a los finales del Preclásico Medio, con excepción de unos tiestos muy hondos en Chalahuite que corresponderían al Preclásico Temprano. Así parece ser que en cuanto a la decoración negativa, el centro de Veracruz se relaciona más con el Altiplano Central que con el sur de Mesoamérica. Pero hay mayor complejidad en la encontrada en Remojadas y El Carrizal, como puede verse en esta descripción de García Payón (1966: 29):

Sobre un fondo rojo con huellas de mica, hay series de anchas franjas ondulantes de color bayo oscuro o negras, también colocadas verticalmente en la pared interior de la vasija.

2. En segundo caso tenemos una vasija tetrápode que fue descubierta en la ofrenda más profunda de Remojadas (Medellin, 1960: 23 y figura 2). Es totalmente típica del Protoclásico de la zona maya, sobre todo de la fase Holmul 1 (Merwin y Vaillant, 1932, láminas 20f y 29a); en una conferencia sobre cerámica maya se señaló a este tipo de vasija como rasgo marcador del Horizonte Chicanel Tardío (Culbert, 1967: 98). La forma de Remojadas recuerda a un tetrápode con pies cilíndricos, huecos y con un agujero pequeño y redondo, encontrado en Monte Albán II (Caso, Bernal y Acosta, 1967, figura 207a). Dada su distribución sureña, no nos sorprende su escasez en el centro de Veracruz, pues parece ser un elemento importado. Otro tetrápode, excavado en el montículo 36 de El Carrizal en un entierro de carácter intruso, fue fechado por la arqueóloga en el Clásico Tardío por ser barro naranja sin desgrasante (Cuevas, 1970, ms.: 38-40). Sin embargo, el primer ejemplo de Remojadas nos ayuda a fechar los principios de Remojadas Inferior en el Protoclásico, a pesar de su carácter asociado generalmente al Preclásico Tardío.

3. El tercer elemento distintivo o marcador del Horizonte Protoclásico, encontrado en El Carrizal, también puede ser una pieza importada, como el tetrápode de Remojadas. Muestra una cabeza de serpiente emplumada, de perfil, raspada sobre dos tiestos, de borde volado, de un cajete de fondo plano (figura 4). Viene de un nivel bastante profundo del montículo 15 (Cuevas, 1970, ms. 53). Su tipo de cerámica "café con baño rojizo" constituye una categoría aparte para Cuevas y, como sólo 
se encontraron dos tiestos de este tipo, es probable que se trate de cerámica importada.

El diseño representado sugiere también un carácter ajeno al sitio. La serpiente vista de perfil y sin mandíbula, se encuentra tanto en las esculturas monumentales izapeñas de la vertiente del Pacífico de Guatemala y Chiapas (Miles, 1965, figuras 2 a, b, 3 e-h, 8 a, c, g; Quirarte, 1973, figura 12) como en Veracruz, por ejemplo, el carapacho de tortuga de Cerro de las Mesas, entierro II-18 (Parsons, 1967: 175). Los lados del Monumento $\mathrm{D}$ de Tres Zapotes tienen este mismo tipo de perfil ofidio con la nariz señalada por una media rosca colocada encima de la vírgula, en forma de $\mathrm{C}$, que compone el labio superior de la boca del monstruo. El perfil que aparece en el tepalcate del Carrizal también presenta esta rosca encima de la curva, que en forma de $S$, adopta el labio superior. Frente del labio hay restos de una vírgula que semeja un ancho signo de interrogación y que muestra una línea paralela, interior; la misma forma, sólo que al revés se encuentra frente a la cabeza del Monumento $\mathrm{D}$ de Tres Zapotes. E1 Monumento $\mathrm{C}$ del mismo sitio -la caja grande de piedra- presenta vírgulas que tienen semejanza estilística a las que componen la cabeza del tiesto de El Carrizal, ya que sus curvas no tienden a la forma cuadrada como las del Monumento $\mathrm{D}$, sino son suaves y fluidas. Aunque siempre se pensó que las vírgulas del Monumento $\mathbf{C}$ representaban solamente al agua, o posiblemente al viento, que salia de la boca de una gran cara frontal, ahora es posible reconocer perfiles ofidios (sobre todo a la derecha del lado A), gracias a su semejanza con el perfil del tepalcate de El Carrizal. Los elementos en forma de roscas redondas que caen bajo el labio abierto serían los dientes, y los elementos que aparecen por atrás, que son más cuadrados, representarían los colmillos. La misma cara ha sido tallada, en forma naturalista, en el Hueso 3 de Chiapa de Corzo, incluyendo la vírgula atrás de la cabeza. Los motivos que semejan plumas y que se yerguen sobre la cabeza de EJ Carrizal se duplican, aunque de manera simplificada, en la serpiente de la Estela 3 de Izapa, y en forma más elaborada (con líneas internas como en El Carrizal) en la máscara llevada por el personaje de la Estella 11 de Kaminaljuyú. Gracias a estas semejanzas podemos fechar el tiesto de El Carrizal en la época tardía del Horizonte Izapeño. Sin embargo, la composición del diseño de El Carrizal se distingue de los otros por la manera en que se formó el ojo de reptil, yuxtaponiendo dos curvas ondulantes que se unen al centro; normalmente el ojo es una 
hendidura cuadrada limitada por la ceja y la boca. Esta variación demuestra una mayor libertad que, tal vez, se permitía en la cerámica, pero no en la escultura monumental.

De este análisis podemos concluir que Remojadas Inferior cae dentro de la época que denominamos Protoclásico, dentro de la etapa más temprano del mismo. ${ }^{2}$ Corresponde a la fase Horcones de Chiapa de Corzo (Chiapa VI), a Monte Albán II, a Chicanel Tardío y Holmul I del área maya, y a Cerro de las Mesas ir en la Mixtequilla. En nuestro calendario las fechas correspondientes serían, aproximadamente de 100 a. C., hasta 100 d. C.

Los dos yugos que aparecen durante esta fase en El Carrizal están relacionados a los estilos artísticos de aquella época: el posolmeca y el izapeño. El primer estilo selecciona algunos temas y simplifica las formas difundidas por los olmecas del Preclásico Medio. Es muy característico de dicho estilo la aplicación de una representación plana a una superficie de forma redonda (wrap-around). Es también típico de esta fase que cada pueblo que había estado bajo el dominio olmeca, escogió y continuó sólo una técnica de las varias que antiguamente practicaba dicha cultura. ${ }^{3}$ Más al sur de la zona semiárida de Remojadas y El Carrizal, encontramos en la zona de Los Tuxtlas una tradición posolmeca en el labrado de piedras de grandes dimensiones; esto se explica por el hecho de que en Los Tuxtlas se localizan las canteras de basalto que surtieron a los grandes centros olmecas (Williams y Heizer, 1965). En Cobata y Cerro El Vigía, en Tres Zapotes y Tlapacoya Arriba, en Piedra Labrada e Ixhuatlán, y en El Mesón, algunos monumentos basálticos de rasgos burdos no corresponden de manera clara a los patrones olmecas. ${ }^{4}$ En dos de estos lugares, Tres Zapotes y El Mesón, tenemos pruebas de asentamientos importantes en el Preclásico Tardío y en el Protoclá-

2 Muchos arqueólogos (por ejemplo, Medellín 1960:177) no emplean la fase protoclásica en su cronología de Mesoamérica, pasando directamente del Preclásico Superior al Clásico Temprano. Sin embargo, considero que la validez del concepto del Protoclásico ha sido probada por la existencia de marcadores de horizonte, sobre todo en el estilo izapeño.

3 Lo discutí con mayor detalle en una contribución que presenté al XLI Congreso Internacional de Americanistas en México, 1974.

4 Los monumentos citados arriba son: Cobata, Mon. 1; Cerro el Vigía, Mons. 2 y 3; Tres Zapotes, Estela A, Mons. F, G, L. R, S; espiga de Tlapacoya Arriba (Stirling 1943, lámina 15b); Piedra Labrada, dos metates, fragmento de figura femenina; Ixhuatlán, fdolo actualmente en el Parque Olmeca, Villahermosa, El Mesón, obelisco y Mon. 1 de ingenio Angel R. Cabada. 
sico, pero hay solamente una ligera ocupación en el Preclásico Medio (Ortiz, 1975 ms.; Scott, $1975 \mathrm{~ms}$ ). La columna basáltica, de formación natural, del ingenio Ángel R. Cabada (De la Fuente, 1973, núm. 208) muestra una figura "danzante", semejante a los famosos Danzantes de Monte Albán por sus líneas fláccidas y por su técnica de relieve realizada con perfiles hundidos por martillazos (Scott, 1971 ms.: 112-3); el relieve se continúa a los lados, rodeando los contornos naturales de la piedra. En el Monumento $F$ de Tres Zapotes se adaptaron los rasgos antropomorfos - brazos y cabeza "negroide"- a una forma funcional: la espiga, posiblemente de uso arquitectónico.

El estilo posolmeca aparece en forma muy clara en dos monumentos relacionados, tanto por su composición, como por su tema. Los dos n:uestran los rasgos de un sapo agazapado rodeando un disco cuya superficie superior es lisa y ligeramente cóncava; se trata de una forma funcional a la cual se rodeó con motivos en bajorrelieve. El monumento que proviene del sitio de Piedra Labrada, cerca del volcán de San Martín Pajapan (figura 5), fue descrito, pero no ilustrado por Blom y La Farge (1926: 41), quienes lo llamaron un metate grande, dando como sus medidas un metro por $23 \mathrm{~cm}$ (en realidad mide 97 por $34 \mathrm{~cm}$ ). En este sitio no se ha podido probar la existencia de una ocupación temprana, ya que en un reconocimiento superficial de la zona no se halló cerámica preclásica (Marco Antonio Reyes López, informe personal), ni tampoco se encontró la gran escultura femenina de piedra reproducida por Blom y La Farge (1926: 42), la cual tiene rasgos claramente olmecas. El otro monumento (figura 6 ) es de El Carrizal y se descubrió casi sobre In superficie del montículo 15, entre relleno de piedra (Cuevas, 1970 ms. 40). Más chico que el "metate" de Piedra Labrada, tiene una depresión circular en la espalda que sugiere que sirvió de metate para moler plantas ceremoniales. El grande podría haber servido para fines semejuntes, o podría haberse utilizado como banquillo para el adivino que se comunicaba con el otro mundo (Lathrap, 1975: 45-7). El sapo Bufo marinus, según los estudios de Furst (1974: 89), toma el papel en la mitología indígena latinoamericana de una deidad terrestre, femenina, con rasgos felinos, la cual da y destruye la vida. Su veneno subcutáneo fue empleado, como droga alucinógena, en San Lorenzo desde la época olmeca.

Durante el Protoclásico la tendencia del estilo posolmeca hacia lo burdo fue superada, en parte, por un segundo estilo artístico, ejempla- 
rizado en el sitio de Izapa, en el Estado de Chiapas. En este sitio, y correspondiente al desarrollo temprano de dicho estilo, quizá todavía dentro del Preclásico Tardío, encontramos dos ejemplos de altares, el 1 y el 2, en forma de sapos agazapados, cuyo modelado no es de muy buena calidad. El Altar 1, más anguloso, presenta mayor similitud con los metates de Veracruz ya citados, y las líneas que representan sus piernas son muy parecidas a las de los yugos de El Carrizal. Posteriormente, en el Protoclásico, habiendo llegado el estilo izapeño a su madurez, se modelan mejor las formas, no solamente en sus perfiles sino también en la curva de sus superficies. Este modelado de formas puede notarse en el gran monumento de Kaminaljuyú que semeja un tazón, y al cual se le conoce como el Altar 3; en esta escultura, un bloque cilíndrico de poca altura, se transformó en un sapo (fig. 7). La piedra fue labrada para representar en bulto al sapo, con volúmenes redondos y líneas precisas, mientras que los ejemplares posolmecas se componen únicamente de perfiles planos, definidos por martillazos y no cincelados, como sucede en el ejemplar de Kaminaljuyú. La misma transformación puede notarse en otra forma posolmeca, me refiero a la figura masculina, de amplios hombros, sentada sobre un banquillo. Un ejemplo de este tipo de escultura, bien tallada y de líneas precisas que sabemos que proviene de contextos protoclásicos de Chiapas (Navarrete, 1972: 50), muestra un cambio estilístico en relación a otro ejemplar, que considero más temprano y más cercano a las tendencias posolmecas, ilustrado por Navarrete (1972, lámina 3). La forma de este último es más burda, con la piedra martillada en lugar de cincelada, por lo cual los detalles carecen de precisión y agudeza.

La aplicación de perfiles agudos y de un sentido de volumen a una composición plana que rodea una forma funcional, como la de los metates, explica el origen estilístico de los dos yugos del entierro de El Carrizal (tiguras 8 y 9). De la época Preclásica Tardía no contamos con ejemplares de sapos adaptados a piedras en forma de $\mathbf{U}$, pero a pesar de ello, y de que los yugos más tempranos que se conocen pertenecen al Protoclásico, creo que el origen de esta forma viene desde el estilo posolmeca. F.1 yugo liso encontrado por García Payón, en El Trapiche, quizá pueda fecharse en el Preclásico, como él mismo sugirió (1947: 327); pero el problema radica en la manera en que se le rescató, ya que no se pudo excavar en su contexto de cerámica. La ocupación de El Trapiche abarca desde el Preclásico Temprano hasta el Tardío, pero el yugo pudo haber 
sido una ofrenda posterior de carácter intruso. El yuguito miniatura (9.8 $\mathrm{cm}$ de largo) hallado en Las Higueras en contextos protoclásicos (figura 3, izquierda, segundo de abajo) puede haber continuado una técnica practicada desde el Preclásico Tardio; representaría, en pequeño, la forma hipotética que tendrían los grandes yugos posolmecas. La superficie está toscamente labrada, faltándole líneas claras a los detalles y los rasgos faciales se redujeron a los mínimos: dos ojos redondos y una ceja.

Ya establecidas las diferencias formales entre los estilos posolmeca e izapeño, podemos ver que los dos yugos de El Carrizal tienen rasgos de ambos. Si consideramos otro yugo del mismo sitio, comprado por la arqueóloga Cuevas (figura 10), veremos la forma esencial posolmeca, sin la finura, pulimento y nitidez del arte izapeño. En él podemos percibir la concepción básica posolmeca de líneas martilladas alrededor de una forma funcional, no escultórica, nótese, por ejemplo, la falta del modelado redondeado del cuerpo lateral limitado por las piernas; aunque débe tomarse en cuenta que quizá esta impresión esté acentuada por el desgaste de la superficie porosa de origen volcánico del objeto. Comparándolo con el yugo de piedra gris, con cinabrio, excavado en el montículo 38 (figura 9), vemos que tienen los mismos rasgos: la lengua ancha saliendo de la boca; la pata delantera que se extiende hacia atrás con una forma compleja en la coyuntura del codo que también se prolnnga hacia atrás; la composición de las curvas que forman la pierna trasera, y el elemento en forma de pico que aparece sobre la ceja y que termina en el borde del yugo. La única diferencia parece ser la forma más larga del ojo y la falta de los párpados laterales. Si es que hay diferencia cronológica entre ambos, dudo que fuera muy grande. Debemos recordar que todo el sitio de El Carrizal probablemente pertenece al Protoclásico Temprano, con excepción de algunas ofrendas de carácter intruso que son posteriores. ${ }^{5}$ Pero como todos los sitios en la zona semiárida de la cultura Remojadas, El Carrizal conserva muchos rasgos del Preclásico Tardío; en realidad, si no hubiera algunas piezas de comercio que nos recuerdan la existencia del Protoclásico sureño, tal vez sería mejor no hablar de un Horizonte Protoclásico más al norte de la Laguna de Alvarado.

5 Las ofrendas posteriores al Protoclásico en El Carrizal son: un tetrápode de barro "naranja sin desgrasante", asignado al Clásico Tardio y enterrado con un cadáver, en un piso que fue removido en el Mont. 36; y cerámica Azteca IV (Cuevas, 1970 ms. 38-40). 
Los dos yugos del entierro 2 tienen la superficie bastante bien pulida y las aristas formadas por la unión de planos son claras y muy definidas. El modelado se realiza en bulto, lo cual es más característico del estilo izapeño y no solamente por líneas; puede notarse este tratamiento, sobre todo en la sección del cuerpo que queda entre las piernas; en los codos de las piernas delanteras; en los ojos protuberantes y en las bandas que forman la $\mathrm{Y}$ de la nariz y de la frente. Pero a pesar de la impresión de semejanza entre los dos, hay diferencias que pueden ser importantes en el desarrollo de la forma prototípica del yugo-sapo.

A mi parecer, el yugo de la figura 8, tallado en una dura piedra verde, tiene una composición singular, diferente de los otros yugos conocidos. Fl diseño se compone de dos curvas hiperbólicas: se acercan, aunque no se tocan, para luego alejarse de nuevo. La de arriba forma un gran círculo casi completo, que cruza la frente, donde acaba por desaparecer; a los lados se dobla en ángulo llegando hasta medio abdomen. Alli casi toca el arco del otro ćrculo fragmentado (por abajo el yugo no tiene njngún motivo esculpido), pero luego oscila hacia arriba, una vez más, para flexionarse encima y formar la penúltima línea que aparece a cada jado del yugo. Debido a esta extraña composición, este yugo no tiene ni el cuerpo ni las piernas traseras, tal como aparecen en casi todos los otros yugos-sapos. Viendo desde arriba al yugo, una curva que parece como si fuera a formar parte del muslo, se transforma en una línea vertical que divide los lados a la mitad, pero no corresponde a ningún rasgo anatómico. La misma curva corta al muslo de cada pierna, dividiéndolo y evitando que se forme una placa gruesa en el hombro. Dos detalles de la cara difieren en relación al otro yugo, además de ser singulares: la lengua, representada entre los labios, pero que no se extiende hacia abajo del inferior; y los ojos que se tallaron como óvalos ligeramente hundidos, dando la impresión de ser las pupilas que aparecen bajo los párpados semiabiertos de un gran sapo.

Hay cierta oposición entre la ingeniosa composición hiperbólica y la representación medio realista del sapo. Por ello, creo que fue un experimento que, por no resultar exitoso, nunça se repitió. Pero cpor qué utilizó el artista esta composición hiperbólica? Creo que posiblemente tenía un simbolismo metafórico que estimuló al artista a tratar de aplicarr esta composición abstracta a la imagen del sapo, ya representada con anterioridad en metates, altares, yuguitos y tal vez en otros yugos de aquella época. Recordemos que el sapo probablemente representaba 
al monstruo de la tierra, al igual que el Tlaltecutli entre los mexicas (Palacios, 1943: 18; Medellín, 1960: 103). Si el yugo hubiera servido únicamente como ofrenda al difunto, su simbolismo se referiría exclusivamente al inframundo. Pero si los yugos, originalmente, fueron usados como cinturones durante el partido de pelota, entonces el simbolismo fodría señalar la yuxtaposición del inframundo y el cielo. La pelota representaba al orbe astral que continuaría moviéndose mientras que los jugadores se sacrificaran para lanzar la pelota, una vez más, al aire. Los jugadores hacían todo Io posible para prevenir que la pelota cayera inmóvil en contacto con la tierra, lo cual simbolizaría la muerte (Borhegyi, 1964: 86). Entonces, los dos círculos hiperbólicos en el yugo representarían el acercamiento de los dos mundos: el celestial y el subterráneo, justo lo que simbolizan el juego de pelota y los cinturones asociados a él.

El otro yugo de piedra gris con cinabrio (figura 9), tiene una gran semejanza con varios otros yugos conocidos hace tiempo (por ejemplo, el de la colección Uhde en Berlín, publicado por Strebel, 1890, lámina vi, núm. 17). La comparación más interesante, sin embargo, es con el yugo cbtenido por Stirling y Weiant en una milpa cerca de Lirios, un sitio aledaño a Tres Zapotes (Weiant, 1943, lámina 67a; Bernal, 1970, figura 1). La única diferencia, muy sutil, entre éste y el yugo gris de El Carrizal, es que el primero tiene los ojos un poco más redondos por abajo y no descansan directamente sobre el labio superior. Pero en todos los ocios rasgos y en su estilo general son casi idénticos. Aunque el yugo de Lirios estaba asociado con cerámica de la fase Superior, otros fragmentos de yugos abiertos, con tallado ornamental, fueron excavados del sitio Ranchito asociados con cerámica Tres Zapotes Medio, mientras que los fragmentos de yugos cerrados estaban asociados con cerámica Tres Zapotes Superior, lo cual llevó a Weiant a pensar (1943: 118) que los yugos abiertos decorados eran más tempranos que los yugos lisos y los cerrados. En este mismo sitio de Ranchito, Weiant (1943: 19) estableció que las vasijas más hondas pertenecen a la subfase $B$ de Tres Zapotes Medio; según el análisis de Coe (1965: 686), Medio B corresponde a una nueva fase, Tres Zapotes II, que se correlaciona con el Protoclásico de Cerro de las Mesas (Coe, 1965: 700). Por eso podemos colocar muchos fragmentos de yugos abiertos y decorados de Ranchito en el Protoclásico, igual que los dos de EI Carrizal.

Los fragmentos de yugos encontrados como material de relleno no 
permiten establecer la fecha original de su manufactura, solamente nos dan un post quem: una fecha límite, después de la cual no pudieron haberse elaborado. Otros hallazgos de yugos en contextos más tardíos no prueban que hayan sido labrados contemporáneamente al depósito, sobre todo cuando consisten únicamente de fragmentos. Cuando se depositan enteros, como ofrendas, por ejemplo en el caso del yugo de El Zapotal, es mucho más probable que fueran hechos poco antes del depósito, aunque al recordar la gran ofrenda de jade de Cerro de las Mesas nos damos cuenta, que en la misma región había un gran número de objetos valiosos que se habían guardado por muchas generaciones. Por eso creo que el fragmento del yugo-sapo encontrado en Las Higueras en contexto Clásico Tardío (figura 11) y bajo una estela pequeña circular (Arellanos Melgarejo, informe personal) podría haber sido una reliquia obtenida de los restos de una importante ocupación protoclásica del mismo sitio, ya que el yugo muestra el mismo estilo que el yugo gris de El Carrizal. Todos pertenecieron, originalmente, al Protoclásico, inclusive el yugosápo de Lirios, Tres Zapotes, hallado en asociación con cerámica clásica.

El yugo recién descubierto en El Zapotal, que pertenece al Clásico Tardío según el arqueólogo Torres Guzmán, es el único otro ejemplo de yugo-sapo en ofrenda, in situ, que es más tardio que los de El Carrizal. Hay muchas semejanzas en la forma de representar el sapo entre el yugo gris de El Carrizal (figura 9) y el yugo esculpido en piedra blanca de El Zapotal: las piernas traseras están agazapadas de igual manera; una sección del cuerpo separa las dos piernas laterales; las piernas delanteras están flexionadas a los lados de la mandíbula; y las patas tienen extensiones por detrás faltando, en ambos ejemplares, las garras. Ambos tienen, además, la boca abierta con ancha lengua extendida hacia abajo y las ventanas de la nariz abocinadas y con aplicación de cinabrio; éstas en su interior tienen forma de $\mathrm{Y}$, al prolongarse los brazos de la misma se forman las cejas y, posteriormente, los hombros circulares. Pero hay también diferencias marcadas entre ambos. Las cejas del yugo de El Zapotal no tienen bandas centrales extendidas hacia arriba y hacia atrás, y sus hombros no están encajados con las piernas delanteras, como es común en los yugos de El Carrizal y varios otros semejantes. Los lados de la boca del yugo de El Zapotal están demasiado extendidos hacia atrás, y sus ojos son alargados y de altura reducida, adquiriendo una rígida forma rectangular; les falta la curva abultada de los yugos de El Carrizal que hace que suban por encima del nivel de 
la cara. En realidad, los rasgos del yugo de El Zapotal están reducidos a placas o planos, casi todos al mismo nivel, separados por ranuras lisas y redondeadas de la misma anchura aproximadamente. En lugar de las formas redondas y orgánicas de los yugos de El Carrizal, el yugo de El Zapotal está reducido a una abstracción angular, habiendo perdido el sentido vital del sapo-monstruo, evidentemente a causa de la repetición, a través de los siglos, de la misma forma.

Dado el estilo angular y reducido de la imagen del sapo-monstruo que decora el yugo de $\mathrm{El}$ Zapotal ¿cómo podríamos explicarnos su aspecto diferente en relación a los yugos, finamente modelados y grabados con entrelaces, los cuales han sido atribuidos al Clásico, tanto por Proskouriakoff, como también por otros autores? Desgraciadamente ninguno fue hallado en excavaciones controladas y, en la mayoría de los casos, desconocemos hasta su procedencia. Pero hay tres posibles respuestas a esta pregunta:

1. Una posibilidad es que los entrelaces sean contemporáneos a los yugos-sapos de El Carrizal, una idea sugerida por el yugo del Museo del Hombre de París (figura 12). Este yugo fue encontrado, junto con puntas de obsidiana y vasijas de cerámica, por Génin, en un montículo localizado en el Rancho del señor Eugène Garabot en El Carrizal (Génin, 1928:523). No he podido localizar las vasijas ni las puntas del mismo montículo; tampoco he podido encontrar el antiguo rancho de Garabot, pero es posible que aquel yugo viniera del mismo sitio que más tarde exploró la señora Cuevas, quien lo consideró de ocupación Preclásica, exceptuando algunas ofrendas superficiales. Aunque la forma general del sapo que decora el yugo de Génin es muy semejante a los sapos de los yugos excavados en El Carrizal, hay algunas diferencias importantes, además de la presencia de entrelaces en el cuerpo lateral. El yugo de Génin tiene dos cabezas de perfil labradas en las terminales del yugo, además de presentar la nariz chica y redonda, más al estilo del jaguar que de la serpiente representada en los dos yugos excavados; muestra, asimismo, un error en cuanto al tratamiento de las ventanas de la nariz, representadas por las hendiduras que aparecen a cada lado del hocico de los ofidios. Por último, el arista de la frente es mucho más pronunciada en el yugo de Génin, y la lengua, aunque extendida como en el yugo gris, no es tan larga ni tan ancha como en éste. Comparando las facciones del yugo excavado con las del yugo de Génin, las de éste último son más suaves y más curvas, lo cual sugiere 
que este yugo es más tardío que los otros dos, posiblemente porque venía de otra parte ajena a la población de El Carrizal.

2. Una segunda posibilidad es que los entrelaces hayan sido labrados en el Clásico, sobre yugos hechos durante el Protoclásico. Dos ejemplos de yugos que fueron "recortados" son conocidos ya en la literatura. El primero, cuyos dos fragmentos fueron dibujados por Seuffert (Bernal, 1970, figura 7) muestra diseños grabados en su interior, en un relieve muy bajo; estos grabados, discontinuos, deben haber sido hechos por orras manos después de la fractura del yugo (Bernal, 1970:25). Considero que las incisiones hechas en el exterior son también añadiduras posteriores, las cuales consisten de: las garras del sapo que se extienden hacia el fondo del yugo, la línea vertical que divide la lengua y las líneas horizontales que señalan los párpados de los ojos. A mi juicio son posteriores por ser incisiones toscas, si se les compara con la escultura en bulto del sapo mismo.

El otro ejemplo de yugo es la famosa pieza de Coatepec en el Museo Nacional de Antropología en México, el cual tiene incisiones finas en el interior que están, según Proskouriakoff; "Grabadas en una manera tan distinta, que opino que fueron hechas por un artista diferente y en otra época" (Proskouriakoff, 1954:76). La imagen del sapo esculpida en el altorrelieve sobre el exterior del mismo yugo (Easby y Scott, 1970, núm. 144) presenta rasgos muy semejantes a los del yugo gris de El Carrizal, pero un poco más gruesos, por ejemplo, nótese la altura y la redondez de las cejas. También se añadieron las garras de los pies y los pliegues, en forma de vírgula, en las muñecas de los pies delanteros. Los entrelaces laterales del cuerpo me parecen contemporáneos al mismo sapo, al igual que los perfiles de cabezas serpentiformes labradas sobre las terminales del yugo. ${ }^{6}$ Pero en cuanto a los otros yugo-sapos con entrelaces, dudo que todos pudieran haber sido "recortados" varios siglos después de su manufactura; hay demasiados yugos de esta clase y la evidencia material en muchos de ellos no sugiere que estén "recortados". 7

B No estoy de acuerdo con Proskouriakoff en relación a que las cabezas representadas de perfil sobre las extremidades del yugo hayan sido hechas por el mismo artista que hizo el diseño interior.

7 Los otros ejemplos de yugo-sapos con incisiones posiblemente posteriores son: cl del Museo de Arte Primitivo de Nueva York (ilustrada en Von Winning 1968: núm. 315-6) y el yugo inédito en la colección del Herbert $F$. Johnson Museum of Art, Cornell University. 
3. La tercera posibilidad se basa en aceptar la continuación del estilo del tallado de los yugo-sapos durante el Clásico, pero solamente en la región más norteña. Los pocos yugo-sapos con entrelaces de los que tenemos procedencia provienen del vértice oriental del altiplano (desde el distrito de Orizaba hacia el norte, hasta Ixhuatlán de Madero (Medellín, 1960, lámina 71), o del altiplano oriental mismo. Esta hipótesis necesita de un estudio más amplio que abarcara todos los ejemplos conocidos, de los cuales sabemos la procedencia. La excepción prueba la regla: el yugo de Tlalixcoyan, municipio vecino a $\mathrm{El}$ Zapotal y que se conserva en Berlín (Strebel, 1890, núm. 29) también es muy lineal, al igual que el yugo de El Zapotal, y tiene la misma proporción achatada de las cejas; además es aún más abstracto que el de El Zapotal y está grabado solamente en la. parte de arriba. Tal estilo caracteriza al bajorrelieve del yugo cerrado de Tres Zapotes (Weiant, 1943, lámina 67-1, b; Bernal, 1970, figura 38); el yugo grabado de Palenque claramente fuera de la zona "madre" de los yugos, tiene sólo una incisión muy ligera sobre la superficie llana (Ruz, 1952, lámina xxvirI). Por eso puedo sugerir, como hipótesis, que la tradición de la escultura en altorrelieve de los yugo-sapos se mantenía en la zona norcentral veracruzana durante el Clásico -zona que posiblemente podemos identificar como la región de asentamiento totonaca.

Finalmente, en el entierro secundario 2 de El Carrizal se encontró yaciendo dentro de la curva del yugo gris - lo tocaba y causó la decoloración amarilla circular- una piedra bien cortada y pulida, de forma perfectamente cilíndrica y con asa en el remate. La arqueóloga consideró que el objeto era un machacador, al igual que otra piedra más burda y menos cilíndrica que apareció en el entierro secundario número 4 del montículo 54 (figura 13). Estos objetos de piedra calcárea pertenecen a la clase de formas denominadas macanas (sling-stones), candados, o manoplas (hand-stones); según opinión de Borhegyi se trata de piedras de mano utilizadas en el juego de pelota (Borhegyi 1961: 138; 1964:84). Esta asociación con el juego de pelota se ve reforzada por el hallazgo de una de estas piezas colocadas dentro de la curva del yugo en El Carrizal. Estos objetos tienen una mayor antigüedad que la originalmente propuesta por Borhegyi, aunque este mismo autor publicó después una piedra redonda con asa que se dijo provenía de La Venta (1967, figura 2). No me parece probable que sea verdaderamente olmeca y del Preclásico Medio; creo que es otro ejemplo 
de piezas posolmecas de La Venta, enumeradas por Squier (1957). Durante el Preclásico Medio, los olmecas empleaban manoplas estilo Knuckle-duster -llanas y semicirculares- aunque no sabemos si servían para el mismo fin (Cervantes, 1969). En Tres Zapotes "eran bastante rzumerosas las piedras en forma de barril con un lado modificado formando una asa" (Weiant, 1943: 119), por lo tanto, las de El Carrizal no son las únicas que se han encontrado. Debemos admitir que ningunos de los hand-stones tienen una forma tan cilíndrica como los dos de El Carrizal, así que no podemos excluir, por completo, la posibilidad de que fuesen machacadores como admitió Borhegyi (1961:129).

La existencia de manoplas de procedencia indudablemente protoclásica, me permite colocar en esta misma época otra manopla de forma semejante aunque menos regular. Alrededor de la misma tiene rasgos en bajorrelieve, típicamente posolmecas, los cuales le dan la apariencia de un felino antropomorfo (figura 4). La piedra en sí tiene una forma irregular, pero muy orgánica; en ella se labraron en bajorrelieve el cuello con sus extensiones, que parecen antebrazos, y las manos descarnadas; ${ }^{8}$ sobre la cabeza aparecen incisiones representando un glifo y una vírgula. Aunque no sabemos la procedencia exacta de la manopla, fue donada al Museo de Xalapa por la Comisión del Papaloapan, lo cual nos induce a pensar que viene de la cuenca del río Papaloapan, cuenca que se extiende hasta las tierras bajas de Oaxaca. De este estado y del periodo Protoclásico proceden imágenes atigradas de Cocijo, Dios de la lluvia, Ias cuales tienen el glifo $\mathrm{C}$ en el centro del tocado y ostentan, además, una larga y extendida lengua bífida. La manopla del Papaloapan también muestra la lengua extendida y además presenta un glifo, ro descifrado, en la frente. Este objeto tiene otra relación más con el Protoclásico, me refiero al asa de la manopla que semeja la sección de un yuguito del Protoclásico de Las Higueras (figura 3, izquierda, 2a. de arriba). Esta manopla tiene el mismo tamaño, proporción y forma (cuerpo y cabeza felina) que Borhegyi (1961:130) observó en los objetos que portan los personajes del relieve del Gran Juego de Pelota

8 La imagen tiene ciertas semejanzas en su técnica de Iabrado, en la composición del cuerpo y en los detalles de la boca, con la gran piedra tallada en bajo relieve y con incisiones de Nopiloa (Medellín, 1960, figura 6d), un sitio que también tiene cerámica protoclásica en su nivel más bajo (Coe, 1965: 699-700). El monolito felino, encontrado en la plaza, tiene el tamaño de una cabeza colosal olmeca, pero mantiene la forma tosca de una roca natural, muy al estilo de las esculturas de Monte Alto, Guatemala, las que considero que representan los ejemplos más sobresalientes del movimiento artístico posolmeca (Easby y Scott 1970: 91-2). 
de Chichén Itzá. La diferencia más importante entre las manoplas tipo Chichén (fechadas recientemente en el Clásico Medio. Parsons, 1969: 177) es que las llevan cogidas de un asa que aparece en el lado de mayor longitud y no en el extremo, como en todos los ejemplos veracruzanos del Protoclásico.

La única forma relacionada durante el Clásico Temprano con el juego de pelota y que no ha aparecido todavía en contextos tempranos, es el tipo de objeto llamado cabeza-hacha. Hay un pequeño grupo de cabezas con una muesca en la parte inferior de su reverso, las cuales tienen la frente llana o ligeramente rizada; muchas veces presentan una aureola marcando la cara posterior del cráneo. Estoy de acuerdo con Proskouriakoff (1954:69) en que:

The simple smoothly curved lines, the lack of any exaggerated forms or any ornamental detail irresistably incline one to the belief that here is an early style, unacquainted with the prolific elaborations of the Classic period. I may be mistaken in this belief, but of all the material. I have examined, these heads seem the most likely to represent prototypes of later specialized forms.

$\mathrm{Su}$ hipótesis acerca de que cabezas semejantes pero con aristas pronunciadas en la frente son más tardías (Proskouriakoff, 1954:70), fue comprobada por el hallazgo de un hacha de este tipo en El Viejón (Medellín, 1960:186-8), asociada a un yugo y a cerámica clásica temprana. El hacha de El Viejón es casi idéntica, a la que ella ilustró en su figura $10 \mathrm{r}$. Las más tempranas, con aureola pero sin las aristas pronunciadas, aunque no han sido encontradas en excavaciones controladas, tienen rasgos marcadamente posolmecas: sus ojos están cerrados, como las de las cabezas colosales de Monte Alto y la manera de labrar la piedra es bastante burda, muchas veces sin emplear líneas de perfiles agudos. Una cabeza inédita del Museo Nacional de Antropología, 4-2016, presenta un hueco por atrás, encima de la muesca, por lo cual se relaciona con otro grupo, poco conocido, que parece venir de La Mixtequilla, como lá de Coyol, cerca de Cerro de las Mesas (Drucker, 1943, lámina 58 a). $\mathrm{Si}$ viene de contextos asociados a la fase Inferior II, que según Coe (1965:686, 697, 702) abarca desde el Protoclásico hasta el Clásico Temprano (fase de la cual procede la cabeza-espiga de roedor excavada en la trinchera 34 de Cerro de las Mesas (Drucker, 1943:80, lámina $58 \mathrm{~b}$ ), entonces los rasgos sí pueden considerarse como una continuación de formas posolmecas, las cuales, sin duda comenzaron más temprano. 
Esta cabeza-espiga de roedor recuerda, especialmente, el uso arquitectónico de las espigas largas con grandes cabezas de Tres Zapotes (monumentos $F$ y $R$ ) que también tienen facciones abultadas y ojos cerrados como las cabezas-hachas.

Del sitio de El Carrizal proceden varios tipos de objetos artísticos asociados con el juego de pelota que antes creíamos que se habian originado hasta el Clásico: yugos con la imagen del sapo-monstruo, manoplas y yuguitos. Todos ellos se originaron, a más tardar, en el Protoclásico y pueden haber estado inspirados en las tendencias artísticas posolmecas que asociamos con el Preclásico Tardío: la tendencia de rodear con líneas grabadas o con bajorrelieves a formas realizadas con fines utilitarios (esto deriva del estilo olmeca, en el cual se grababan imágenes sobre la superficie de otras representaciones); la tendencia de realizar el mínimo esfuerzo en el tallado, en vez de emplear técnicas muy elaboradas que requerían gran número de horas, como lo hacían los olmecas; la tendencia a representar objetos de importancia ritual a semejanza de monstruos terrestres, a veces más felinos, a veces más parecidos a reptiles, lo cual deriva de las grandes caras planas olmecas.

Concluyendo, propongo que los grupos del Preclásico Tardfo, contemporáneos al florecimiento de las tendencias posolmecas, establecieron en el centro de Veracruz las formas de jugar la pelota que se mantuvieron durante toda la época Clásica hasta el Posclásico Temprano. La costumbre del sacrificio por decapitación apareció entonces (Estela 21 de Izapa, Los Danzantes D-78, D-123, y J-112 de Monte Albán, y la Estela A de Tres Zapotes), aś como también la representación de grandes sapos que se utilizaban como altares (Altares 1 y 2 de Izapa, Altar 3 de Kaminaljuyú, "metate" de Piedra Labrada) posiblemente para recibir las ofrendas del sacrificio. Las cabezas de piedra, sean humanas o zoomorfas, representaban a los sacrificados por decapitación; estas cabezas, tal vez, o se ponían a los lados de la cancha (quizá, por eso, tenían espiga), o se llevaban en la mano (de allí que estuvieran huecas, aunque son demasiado pequeñas para usarse como máscaras) . $\mathrm{Al}$ principio del Clásico se les talló una muesca para así poder colocarlas sobre los yugos en las procesiones. La imagen poderosa del sapo, como representante del inframundo (con asociación con lo terrestre), se labró en la cara de los yugos que se empleaban para mantener en movimiento a la pelota, la cual representaba el orbe celestial. Después de la muerte de su dueño, el yugo se enterraba con él para así poder aún 
servirle en su lucha por mantener el universo en equilibrio. Los yugos que tienen la imagen del sapo-monstruo también representaban al inframundo adonde iba el señor difunto. Las piedras de mano, usadas asimismo en el juego de pelota, se depositaban como ofrendas en el sepulcro, ya que a la muerte se le concebía como una extensión de la vida: al morir el sujeto sólo cambiaba de lugar sin sufrir realmente un cambio radical (Benson, ed., 1975:43-4, 95-7, 192). De allí que el señor necesitara tener su equipo para el juego de pelota, para poder seguir jugando en el bajo mundo, como hicieron los héroes gemelos del Popol Vuh.

\section{INDICE EXPLICATIVO DE LAS ILUSTRACIONES}

Todas las fotos son del autor con excepción de las indicadas.

Figura 1. Carrizal, Ver., Mont. 38, Ent. Sec. 2: Olla globular de barro café, $68 \mathrm{~cm}$ alto, cubierto con apaxtle de barro café con baño rojizo, $62 \mathrm{~cm}$ diam. Jalapa. MAUV.

Figura 2. Carrizal, Ver., Mont. 38, Ent. Sec. 2: Vasijas de cerámica izq., café con baño rojizo pulido, $8.7 \mathrm{~cm}$ alto; negro pulido, $21 \mathrm{~cm}$ diam.; café claro pulido; café pulido con decoraciones negativas; café claro pulido. Jalapa: MAUV.

Figura 3. Las Higueras, Ver.: Fragmento de yuguitos de piedra, $16.5 \mathrm{~cm}$ largo máximo. Jalapa: MAUV.

Figura 4. Carrizal, Ver. Mont. 15, Tr. 1: Fragmento de cajete de barro café con baño rojizo y decoración raspada, $17 \mathrm{~cm}$ ancho, $6 \mathrm{~cm}$ alto. Jalapa: MAUV.

Figura 5. Piedra Labrada, Ver.: "Metate" de piedra en forma de sapo, $97 \mathrm{~cm}$ diam. $34 \mathrm{~cm}$ alto. Jalapa: MAUV.

Figura 6. Carrizal, Ver., Mont. 15, Tr. 1: Metate de piedra calcárea en forma de sapo, $38 \mathrm{~cm}$ largo, $8 \mathrm{~cm}$ alto. Jalapa: MAUV.

Figura 7. Kaminaljuyú, Guatemala: Altar 3, de piedra, en forma de sapo, $52 \mathrm{~cm}$ alto. Guatemala: Museo Nacional de Antropología e Historia.

Figura 8. Carrizal, Ver, Mont. 38, Ent. Sec. 2: Yugo-sapo de piedra verde, $41 \mathrm{~cm}$ largo, $35 \mathrm{~cm}$ ancho, $12.5 \mathrm{~cm}$ alto. Jalapa: MAUV.

Figura 9. Carrizal, Ver., Mont. 38, Ent. Sec. 2: Yugo-sapo de piedra gris con cinabrio, $41 \mathrm{~cm}$ largo, $39 \mathrm{~cm}$ ancho, $11.5 \mathrm{~cm}$ alto. Jalapa: MAUV. 
Figura 10. Carrizal, Ver.: Yugo-sapo de piedra gris porosa, $42.5 \mathrm{~cm}$ largo, $38 \mathrm{~cm}$ ancho, $12 \mathrm{~cm}$ alto. Jalapa: MAUV.

Figura 11. Las Higueras, Ver.: Fragmento de yugo-sapo de piedra, $19 \mathrm{~cm}$ ancho, $12.4 \mathrm{~cm}$ alto. Jalapa: MAUV.

Figura 12. Carrizal, Ver., ex-rancho de Gabarot: yugo-sapo de diorita, $40.5 \mathrm{~cm}$ largo, $36 \mathrm{~cm}$ ancho. Paris: Musee de l'Homme, 24.13.3401, regalo de A. Génin. Foto: cortesía del Museo.

Figura 13. Carrizal, Ver.: Izq., Mon. 38, Ent. Sec. 2: Macana de piedra amarilla, $16 \mathrm{~cm}$ alto. Der., Mont. 54, Ent. 4: pito-canino de barro con chapopote, macana de piedra calcárea amarilla, $16 \mathrm{~cm}$ alto. Der., Mont. 54, Ent. 4: olla-efigie de barro. Jalapa: MAUV.

Figura 14. Cuenca del Papaloapan, Ver-Oax. Macana de piedra verde, $32.2 \mathrm{~cm}$ largo, $12.5 \mathrm{~cm}$ alto, $9.4 \mathrm{~cm}$ grueso. Jalapa: MAUV. 